ด

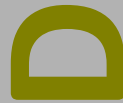

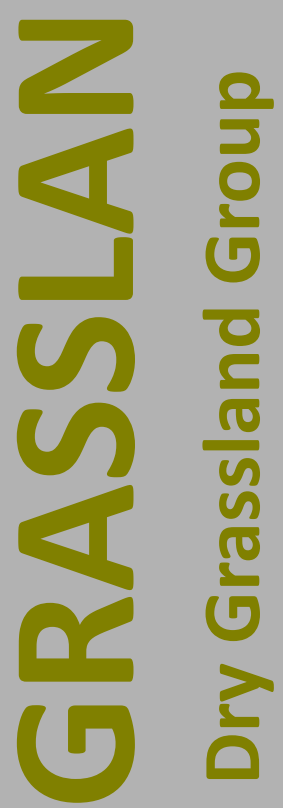

(1) $\frac{1}{10}$

45

(1)

$02+$

10

1

$42 \frac{3}{2}$

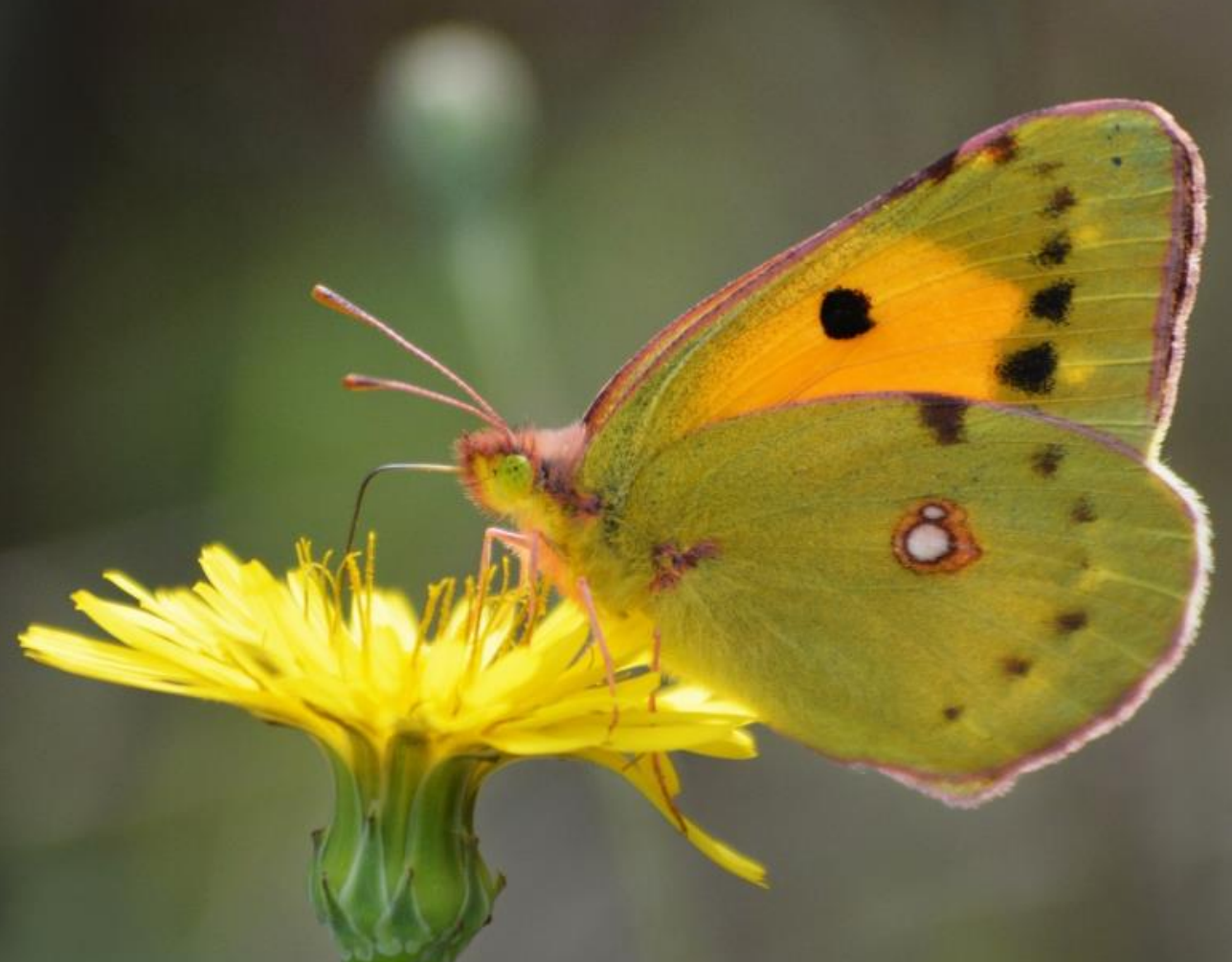




\section{Table of Contents}

Editorial

News

EDGG Events

EDGG Publications

Announcements

Lostrangio \& Clotteau: A review of policy frameworks supporting mountain grasslands in Europe

Photo Story

Best shots on "Grassland birds"

\section{Short Contributions}

Recent Publications of our Members

Forthcoming Events

\section{Palaearctic Grasslands}

ISSN 2627-9827

DOI 10.21570/EDGG.PG51

Palaearctic Grasslands, formerly published under the names Bulletin of the European Dry Grassland Group (Issues 1-26) and Bulletin of the Eurasian Dry Grassland Group (Issues 27-36), is the journal of the Eurasian Dry Grassland Group (EDGG). It appears in four issues per year. Palaearctic Grasslands publishes news and announcements of EDGG, its projects, related organisations and its members. It also serves as an outlet for scientific articles and photo contributions.

Palaearctic Grasslands is freely available at http://edgg.org/publications/bulletin and new issues are announced to all EDGG members. All content (text, photos, figures) in Palaearctic Grasslands is open access and available under the Creative Commons license CC-BY-SA 4.0 that allow re-use provided proper attribution is made to the originators ("BY") and the new item is licensed in the same way ("SA" = "share alike").

Submissions following the Author Guidelines are welcome by the deadlines of the four issues: 31 January, 30 April, 31 July and 31 October.

Scientific articles (Research Articles, Reviews, Forum Articles, Scientific Reports) should be submitted to the Receiving Editor Jürgen Dengler (dr.juergen.dengler@gmail.com) and will then undergo peer review, so publication in a certain issue cannot be guaranteed.

All other text contributions (News, Announcements, Short Contributions, Book Reviews, Glimpses of a Grassland...) should be submitted to Anna Kuzemko (anyameadow.ak@gmail.com) AND Idoia Biurrun (idoia.biurrun@ehu.es).

Photo contributions (photos for general illustrative purposes with captions; Photo Stories) should be submitted to Rocco Labadessa (rocco.labadessa@gmail.com).

Contributions to Photo Competitions should be submitted to Edy Fantinato (edy.fantinato@unive.it)

Contributions to the section "Recent Publications of our Members" should be sent to Iwona Dembicz (i.dembicz@gmail.com) and those for "Forthcoming Events" to Alla Aleksanyan (alla.alexanyan@gmail.com). Any member of EDGG who would like to see their book reviewed in Palaearctic Grasslands should communicate with our Book Review Editor Péter Török (molinia@gmail.com).

Palaearctic Grasslands is published by EDGG c/o Prof. Dr. Jürgen Dengler, Plant Ecology, BayCEER, University of Bayreuth, Universitätsstr. 30, 85447 Bayreuth, Germany.

Palaearctic Grasslands on ResearchGate, Google Scholar, vegsciblog.org

\section{Editorial Board}

CHIEF EDITORS: Idoia Biurrun, Jürgen Dengler, Anna Kuzemko, Rocco Labadessa

SCIENTIFIC EDITORS: Alla Aleksanyan, Didem Ambarlı, Idoia Biurrun, Iwona Dembicz, Jürgen Dengler, Edy Fantinato, Riccardo Guarino, Frank Yonghong Li, Anna Kuzemko, Rocco Labadessa, James Moran, Alireza Naqinezhad, Jalil Noroozi, Arkadiusz Nowak, Salza Palpurina, Ricarda Pätsch, Nina Polchaninova, Solvita Rūsinna, Laura Sutcliffe, Péter Török, Atushi Ushimaru, Orsolya Valkó, Stephen Venn

LINGUISTIC EDITORS: Dolores Byrne, Sean Cooch, Magdalena Firganek-Fulcher, Paul Goriup, Richard Jefferson, Ashley Lyons, Lorna Marcham, Jim Martin, James Moran, Hallie Seiler, Stuart Smith, Laura Sutcliffe, Stephen Venn

PHOTO EDITOR: Rocco Labadessa

PHOTO JURY: Edy Fantinato (Chair), Magdalena Firganek-Fulcher, Anna Kuzemko, Rocco Labadessa, Jim Martin, Jalil Noroozi, Salza Palpurina

BOOK REVIEW EDITOR: Péter Török

LAYOUT AND TYPESETTING: Rocco Labadessa 


\section{Editorial}

Dear readers,

A second year of the Covid-19 pandemic is coming to an end. It is still affecting our lives and our societies in a way that we could not imagine before. I hope that, like me, you could at least be out in the field during the summer and visit many beautiful grasslands with their enormous diversity of creatures. Unfortunately, another Covid winter is approaching, and simulations suggest that it might be as bad as or worse than the previous one, except in the few countries with very high vaccination rates. Therefore, better prospects for next year are important. Then likely nearly everybody will be immunised (by infection or vaccination), and the chances are better for a return to normal live.

There are thus good reasons to be optimistic that in 2022, with two years of delay, EDGG finally will be able to conduct its Field Workshop along the latitudinal gradient in Ukraine
(May) and the Eurasian Grassland Conference in Tolosa, Spain (September). To "survive" the winter, EDGG additionally offers two virtual events: the continuation of our successful Talk Grasslands! Series of last winter and the first ever Asian Grassland Conference to which we expect numerous participants from a wide range of countries. You will find the announcements of all four events in this issue, together with the calls for new grassland-related Special Features, a Photo Story from Central Asian grasslands and various other items.

Enjoy reading and stay healthy,

Jürgen Dengler

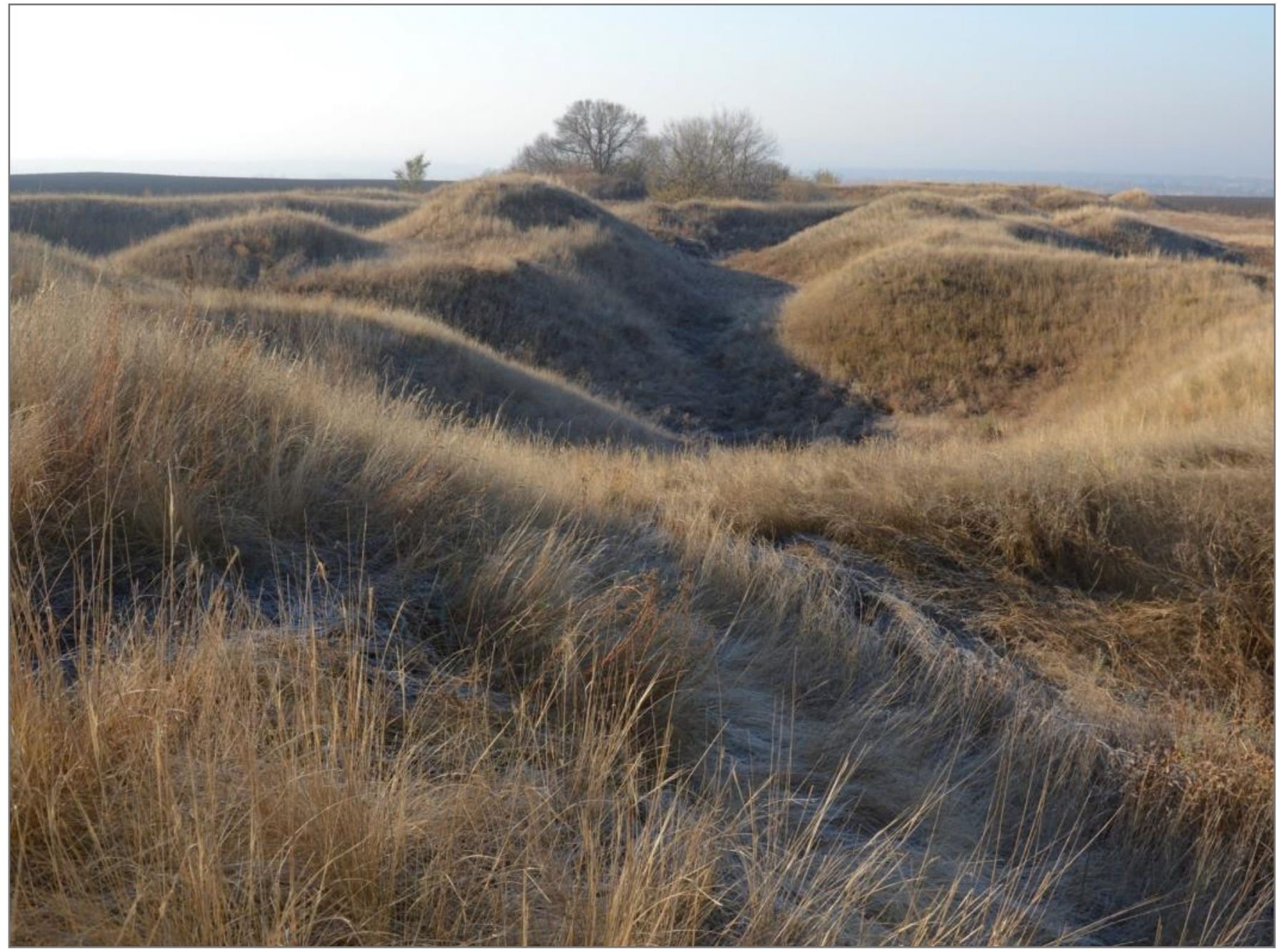

Forb-bunchgrass steppe, dominated by Stipa capillata and Agropyron pectinatum, Cherkassy region, Ukraine. Photo: D. Shyriaieva. 


\section{News}

\section{Call for photos in Palaearctic Grasslands}

As usual, we are looking forward to your contributions to the Photo Story section, as well as your photographs for general illustrative purposes.

Submissions for the Photo Story section are always welcome. Photo Story is an open space where members can submit their own photo collection on a certain grassland-related topic of their choice. High-quality photos should be provided together with their captions (at least species names or landscape description), a brief text and possibly other graphical elements (like a map or a drawing). The selection of photos should fit within 4-12 pages and the contributors should propose a preliminary layout (in PDF or MS Word format), which will be finally typeset by Editors. As an example, you can look at the Photo Stories published in the previous issues.

As with scientific articles, Photo Stories undergo a review process with a focus on photo quality. There is no guarantee that they will be accepted without changes, and late submissions may be published in subsequent issue.

We would also like to encourage you to contribute to the Global Vegetation Project with your vegetation photographs:

1) If your photos have already been published in Palaearctic Grasslands, you can submit them to the global map citing DOI of your article or of the whole issue (you can find all published issues here: https://edgg.org/publications/ bulletin);

2) If you are submitting new vegetation photographs to Palaearctic Grasslands, either within an article, a photo story or for general illustrative purposes, you can provide each photo file with the following information $\left(^{*}=\right.$ required fields): date (year/month/day); author's full name*; place name; latitude and longitude*; vegetation type; vegetation classification system; naturalness; dominant species list*; additional comments.

Please take a look at the project website (http:// gveg.wyobiodiversity.org) for an overview of the global map and the data entry form.

If you want to contribute to Photo Stories, or if you simply want to help us with enriching this aspect of the journal, please submit your photos together with required information to Rocco (rocco.labadessa@gmail.com).

Deadline for photo submissions is $\mathbf{3 1}$ January 2022.

Rocco Labadessa, Italy rocco.labadessa@gmail.com

\section{Call for Photo Competition "Asian Grasslands"}

To celebrate the first Asian Grassland Conference, the overall theme of the new Photo Competition is Asian Grasslands. Asian grasslands are unique worldwide for their variety of habitats, species and land-use practices. The aim of this Photo Competition is to highlight this wealth of immense beauty and conservation value. Participants of the conference, as well as all EDGG members, are invited to send up to three high-quality photographs on any combination of the following topics:

- Asian grassland plants

- Asian grassland animals

- Asian grassland landscapes

- Humans and grasslands in Asia

The photos should be in high resolution (full-size JPEG or TIFF images, at least $300 \mathrm{dpi}$ ) and be accompanied by captions including a short title or description and information on the subject (species name, date, place name). The Photo Jury will select the best photographs. The three best shots in each category will be awarded with full space in the next issue of Palaearctic Grasslands and will be presented in the closing session of the conference. We reserve the right to also use non-winning photos for illustrative purposes in other parts of the issue. Published photos will be licensed under the CC BY-SA, and supporters of the conference can use them with proper credits. If you want to take part in the competition, please submit your photos together with required information to Edy Fantinato (edy.fantinato@unive.it) by 6 February 2022.

Photo Jury: Edy Fantinato (Chair), Magdalena FirganekFulcher, Anna Kuzemko, Rocco Labadessa, Jim Martin, Alireza Naqinezhad, Jalil Noroozi, Salza Palpurina.

Edy Fantinato, Italy edy.fantinato@unive.it

\section{DOIs of Palaearctic Grasslands now working}

After a long struggle, the digital object identifiers (DOIs) of the articles and issues of Palaearctic Grasslands (since issue 37) are now functional. For example, you can use https://dx.doi.org/ to find the pdf of an article. Many thanks to IAVS who made this possible. 


\section{EDGG Event}

\section{EDGG Grassland \\ research and conservation \\ The Asian Grassland Conference is approaching}

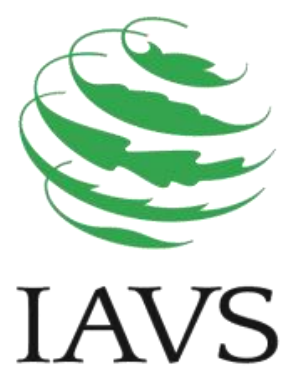

As announced in the last issue of Palaearctic Grasslands, we are pleased to organise the very first Asian Grassland Conference from $\mathbf{2 2}$ to $\mathbf{2 4}$ February 2022. We invite researchers and conservationists from any discipline, who are interested in Asian grasslands, to join us! The Asian Grassland Conference ( $A G C$ ) is a virtual event that is free of charge, owing to the generous support of the International Association for Vegetation Science (IAVS), the mother organization of EDGG.

AGC will provide a forum for participants to learn about advances in the field, get inspired, share knowledge, develop networks and enjoy the event. Regular talk sessions and speed talk sessions (in place of the poster session) will cover all aspects of grassland research and conservation. Three distinguished scientists will give keynote talks: Prof. Norbert Hölzel, from the University of Münster, will show us the impact of Post-Soviet land-use change on Central Asian steppe ecosystems. Prof. Shuli Niu, from the Institute of Geography and Natural Resources of the Chinese Academy of Sciences, will focus on the response of alpine grasslands to global change. Prof. Jiang Zhigang, from the Institute of Zoology of the Chinese Academy of Sciences, will present the status and conservation of the wild ungulates of grasslands in China.

In addition to the oral presentations, we are organizing several workshops and informal meeting opportunities. At the end of the daily sessions, participants will be invited to join a happy hour, where they can interact with other participants and talk. Newcomers interested in learning more about EDGG can join an Introduction to EDGG workshop. Another interactive event is Meet the Editors, where participants can ask questions about all stages of publishing a scientific article, such as submission, evaluation criteria, language issues, or how to reply to reviewers. We will have several editors from high-quality journals, including Restoration Ecology, Applied Vegetation Science, Biological Conservation, Vegetation Classification and Survey, Frontiers of Ecology and Evolution, Hacquetia and Frontiers in Environmental Science, on the virtual podium.

There will be a very important workshop for vegetation scientists on the establishment of one or more IAVS Regional Section(s) for Asia. Not only grasslands scientists but also researchers working on other habitats will be invited.

Another important workshop for scientists dealing with vegetation classification will be the Workshop on the vegetation typologies in Asia and their crosswalks to/overlaps with phytosociological syntaxa. The aim of this workshop is to better understand vegetation typologies of Asia from a global point of view. Specifically, we would like to harmonize Asian typologies with that of GrassPlot, an EDGGassociated database of multi-scale vegetation-plot data of Palaearctic grasslands and other open habitats (https:// edgg.org/databases/GrassPlot).

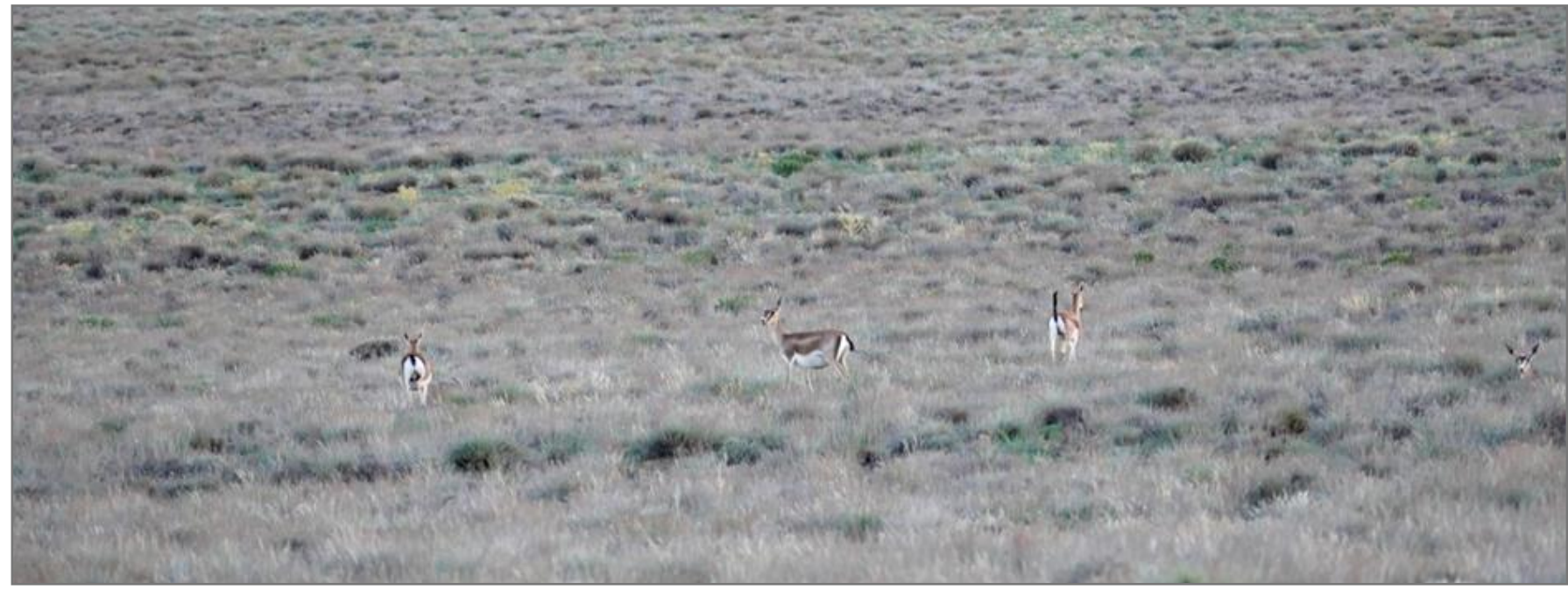


The conference will reward young scientists for an excellent presentation of their research. The Young Investigator Competition will take place in both the oral and poster categories. Applications will be collected at registration. In addition, we encourage all conference participants to participate in the Photo Competition on the beauty and diversity of grasslands in Asia. Please find details on page 4 of this issue.

We are planning to organize three Special Features (SFs) in association with the conference, to give participants the opportunity to make their research more visible. Depending on the subject and quality of their presentation, participants will be able to choose from three SFs in international, peerreviewed journals:

- Biodiversity and Conservation (Chair of Guest Editors: Didem Ambarlı): For the outstanding contributions of the AGC.

- Hacquetia (Chair of Guest Editors: Orsolya Valkó): For more details, see page 13 of this issue.

- Vegetation Classification and Survey (Guest Editors: Jürgen Dengler, Alireza Naqinezhad \& Arkadiusz Nowak): For any paper that deals with the development or application of a classification system of Asian grasslands. For more details, see page 12 of this issue.

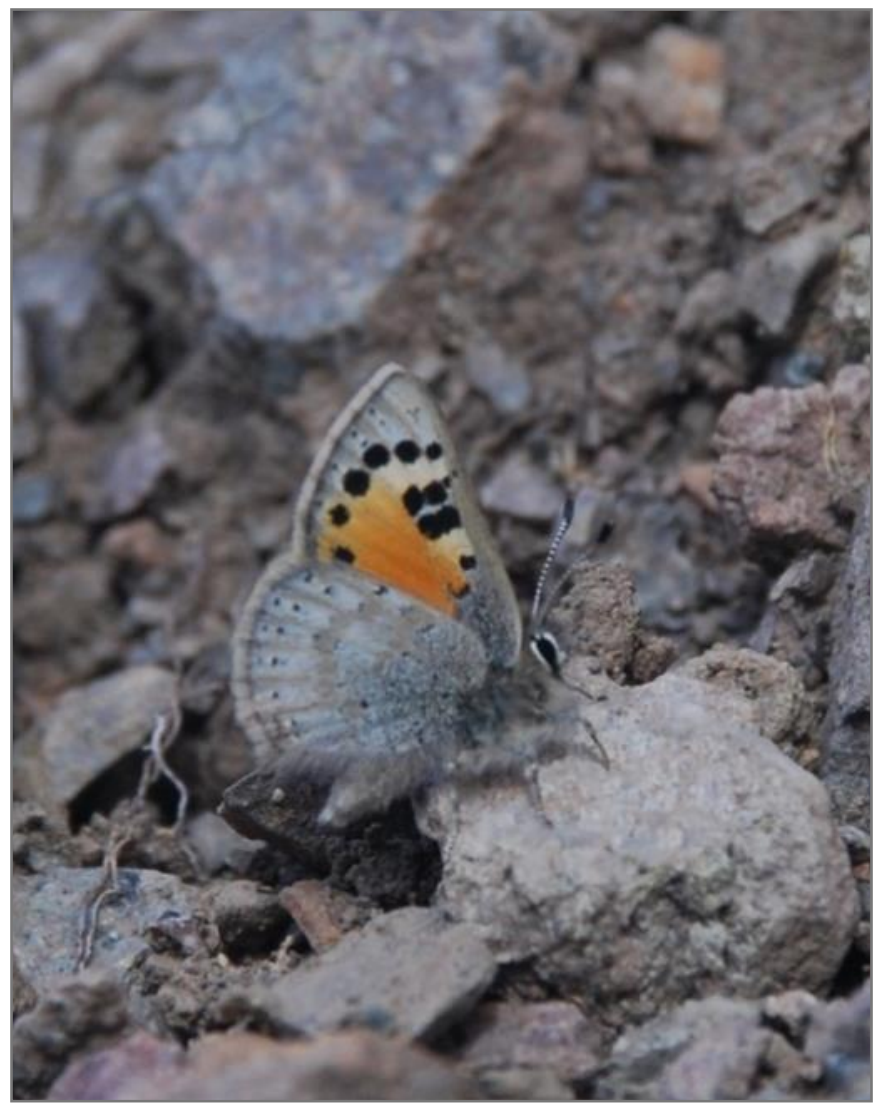

Caucasian vernal copper (Tomares callimachus), Artvin, Turkey. Photo: D. Ambarlı.

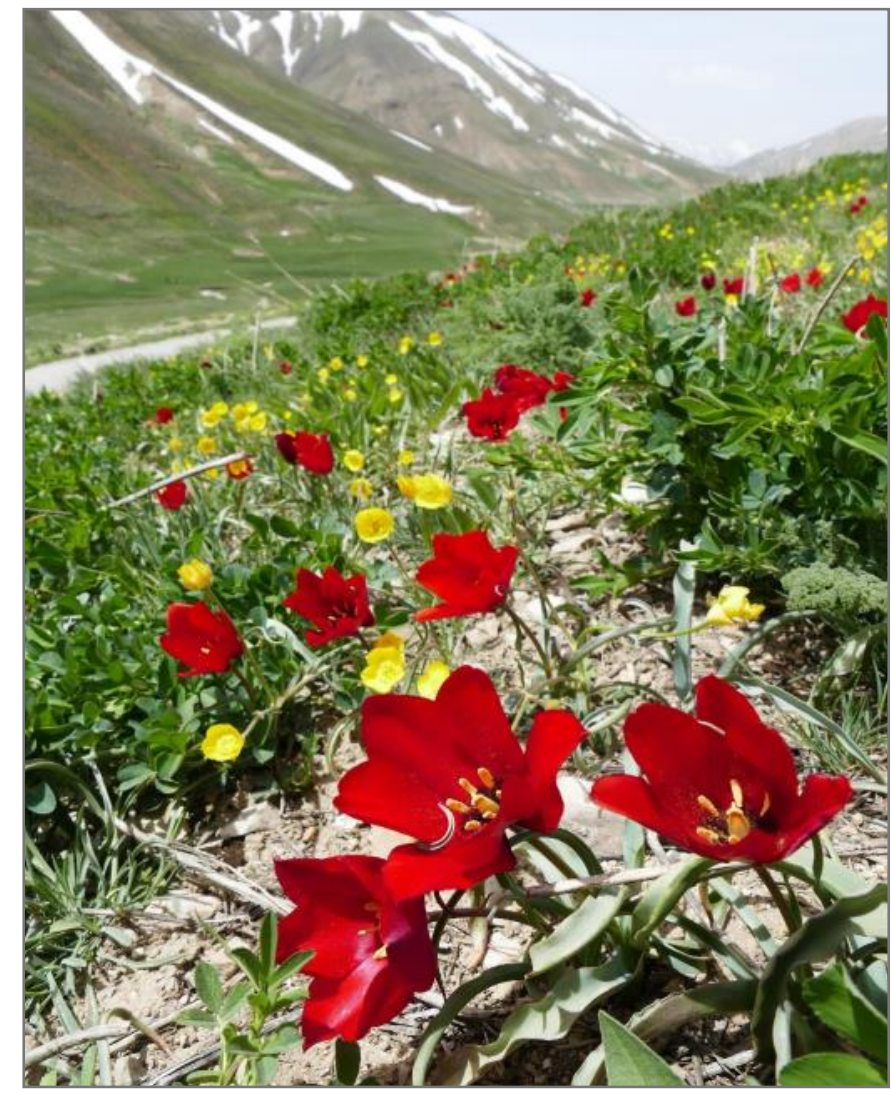

Tulipa montana, Alborz Mountains, Iran. Photo: J. Noroozi.

Please visit the conference website https://edgg.org/AGC for further information. A detailed second call is planned shortly after the release of this issue and will be sent to all EDGG members. Registration will be launched in the first week of December. If you would like to pre-register for the conference, please send an email to edgg.agc@gmail.com.

For any questions, suggestions and requests, please contact the Organizing Committee:

Didem Ambarlı (Chair), Düzce University, Turkey, didem.ambarli@gmail.com

Alla Aleksanyan, Institute of Botany after A.L. Takhtajyan NAS RA, Yerevan, Armenia, alla.alexanyan@gmail.com

Jürgen Dengler, Zurich University of Applied Sciences (ZHAW), Wädenswil, Switzerland, dr.juergen.dengler@gmail.com

Frank Yonghong Li, Inner Mongolia University, Hohhot, China, lifyhong@126.com

Stephen Venn, University of Helsinki, Finland, stephen.venn@helsinki.fi

Jianshuang $\mathbf{W u}$, Chinese Academy of Agricultural Sciences, Beijing, China, wujianshuang@caas.cn 


\section{EDGG Event}

\section{7th EDGG Field Workshop in 2022 Ukrainian steppes along climatic gradients}

Due to the worldwide pandemic restrictions we had to postpone this planned Field Workshop twice - in 2020 and 2021. Finally, after the stabilization of the situation, we are pleased to inform that the Field Workshop will finally be held in 2022 (end of May - beginning of June). The first priority will be offered to those applicants who registered in 2020. Any available places will be advertised in the next issue of Palaearctic Grasslands in February. As planned, we will work in Southern and Central Ukraine within Kherson, Zaporizhzhia, Dnipro, Kharkiv and Poltava administrative regions from the driest semi-desert communities in the south to the meadow steppes in the north (for the details see: Vynokurov et al. 2019, Palaearctic Grasslands 44). The main aim of the Field Workshop will be to investigate plant richness patterns of steppe grasslands along climatic gradients (precipitation and temperature). The exact dates will be announced in the following issue of Palaearctic Grasslands.
Local organizers:

Denys Vynokurov, Kyiv, Ukraine

denys.vynokurov@ukr.net

Ivan Moysiyenko, Kherson, Ukraine

ivan.moysiyenko@gmail.com

Dariia Shyriaieva, Kyiv, Ukraine

darshyr@gmail.com

Nadiia Skobel, Kherson, Ukraine

EDGG Field Workshop Coordinators:

Iwona Dembicz, Warsaw, Poland \& Wädenswil, Switzerland i.dembicz@gmail.com

Idoia Biurrun, Bilbao, Spain

idoia.biurrun@ehu.es

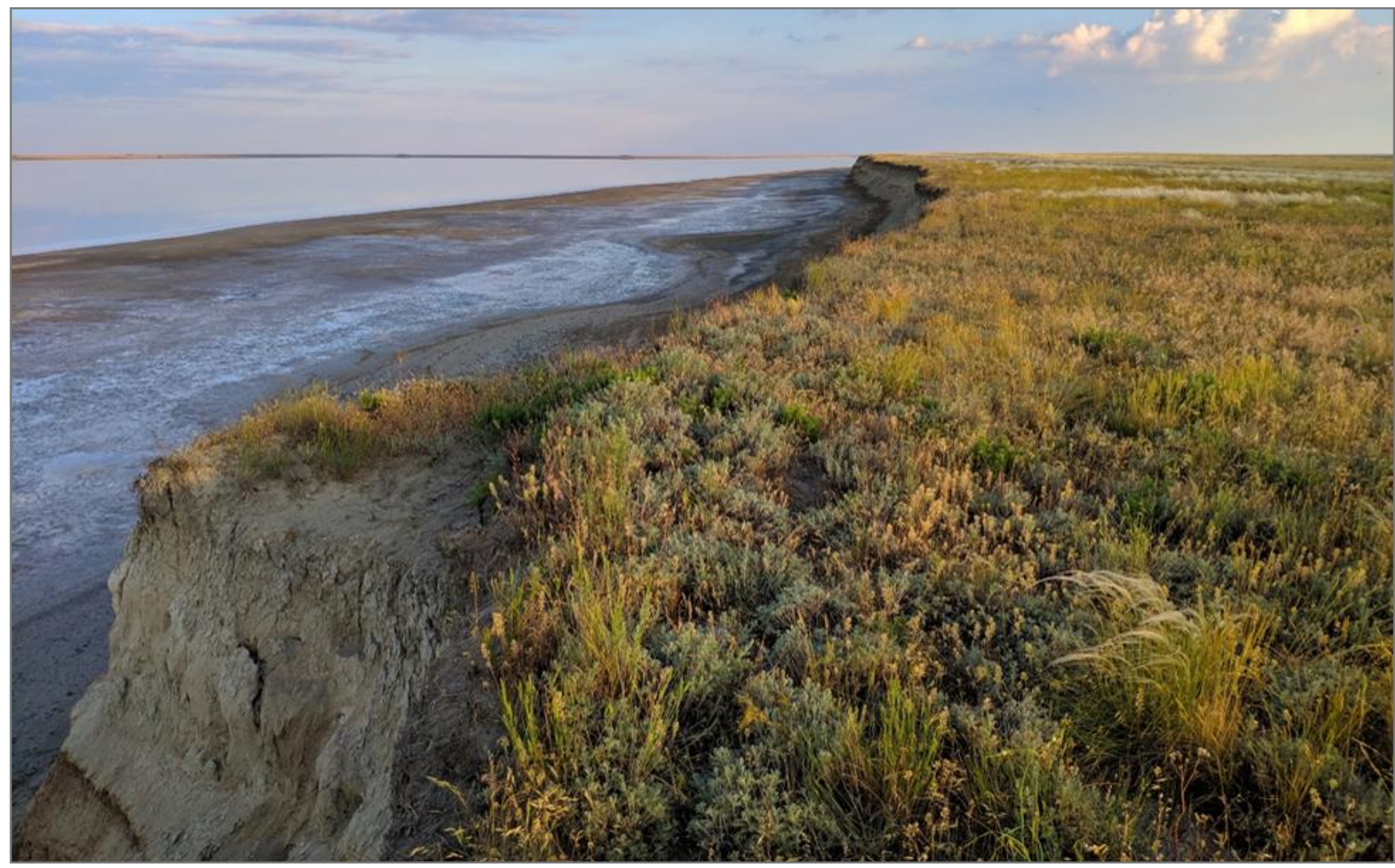

Desert steppes on Churiuk Island, Kherson Region, Ukraine. Photo: D. Vynokurov. 


\section{EDGG Event}

\section{EGC 2022}

\section{Grassland dynamics and conservation in a changing world 17th Eurasian Grassland Conference Tolosa, Spain, 5-11 September 2022 https://edgg.org/egc2022}

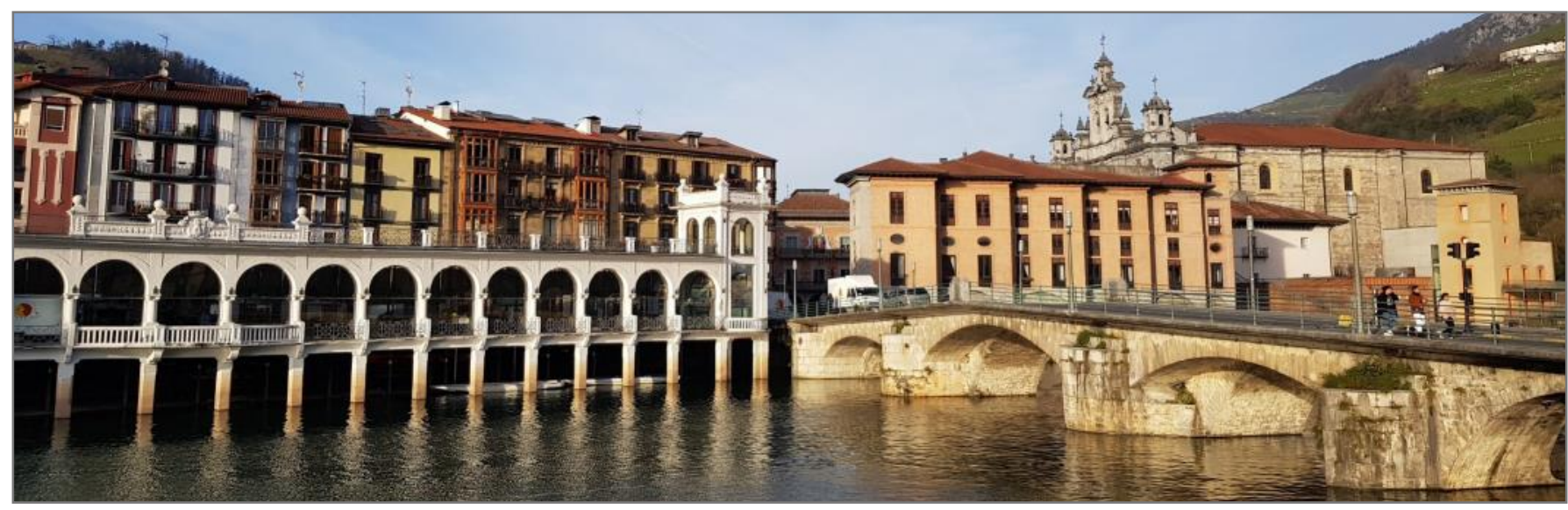

The 17th EGC, first scheduled for September 2020, will be held in September 2022, with a similar program. We will welcome Monika Janišová, Alfonso San Miguel and Frank Yonghong Li as keynote speakers.

The conference will focus on the following topics:

1. Succession and species turnover in abandoned grasslands

2. Biodiversity of urban grasslands

3. Above and belowground grassland diversity

4. Grassland conservation and global change

5. Classification of Palaearctic grasslands and other open habitats

6. Conservation genetics

Preliminary schedule:

5 Sept. Workshops, registration

6 Sept. Talks and poster sessions including keynote lectures by Alfonso San Miguel and Monika Janišová, followed by a touristic tour

7 Sept. Mid-conference excursion, grassland party and auction

8 Sept. Talk and poster sessions including keynote lecture by Frank Yonghong Li, followed by the general assembly and closing ceremony

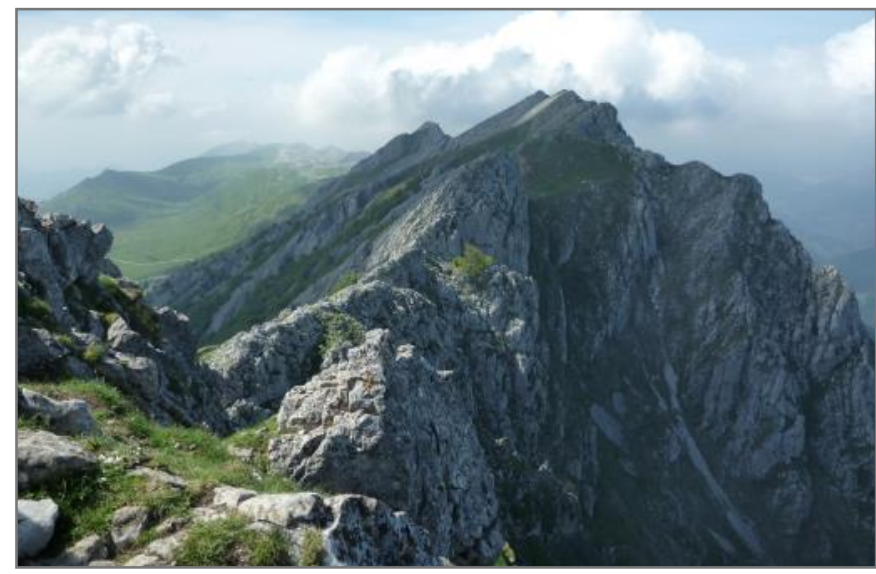

Please visit the conference website for further details: https://edgg.org/egc2022. The full program and further details for registration and abstract submission will also be announced in Palaearctic Grasslands 52.

We hope to meet all of you in Tolosa!!

The local organizing committee:

Idoia Biurrun, Asun Berastegi, Juan Antonio Campos, Itziar García-Mijangos, Javier Loidi, Peter Pearman, Isabel Salcedo, Daniel García-Magro, Diego Liendo, Raquel Ponti.

9-11 Sept. Post-conference excursion through Basque Country and Navarre visiting coastal areas, Basque mountains, Ebro valley and Pyrenees.

\section{EDGG Conference Coordinators:}

Didem Ambarlı, Alla Aleksanyan, Stephen Venn. 


\section{EDGG Event}

\section{Talk Grasslands Winter 2021-22}

- Driving factors of long-term vegetation changes in grasslands. Martin Diekmann 23rd November 2021 14:00 CET

- Linking plants and pollinators: a story of local disturbance events and anthropized landscapes. Paolo Biella 14th December 2021 14:00 CET

- Grasslands: the hidden part. Jitka Klimešová 11th January 2022 14:00 CET

The talks will be broadcast via Zoom (Meeting ID: 61275353870 Passcode: 349764). Each talk will have a duration of 45 mins flowed by Q\&A session. Visit EDGG's Talks page to find more information and links to access the videos after the talks. Please contact the organisers if you have any questions: Stephen Venn stephen.venn@helsinki.fi or Didem Ambarlı didem.ambarli@gmail.com

Driving factors of long-term vegetation changes in grasslands.

\section{Martin Diekmann, 23rd November 2021}

Semi-natural grasslands include various types with much differing species assemblages and habitat conditions: wet grasslands, dry grasslands on calcareous soils, 'acid grasslands' and others. Whatever type, semi-natural grasslands have changed over recent decades, some more, some less. The aim of this talk is to examine the long-term changes of different grassland types and compare the direction and extent of these changes. The main research questions are: How has total species richness changed? Do the temporal trends of habitat specialists differ from those of habitat generalists? And, what are the driving factors - both abiotic and biotic - of the observed vegetation changes?

Based on a large number of re-survey studies, I will try to answer the above questions, focusing on vascular plants and regions in Central and Western Europe. While Festuco -Brometea grasslands (if managed well in nature reserves) are relatively stable over time in both their species composition and overall species richness, Nardus grasslands and especially wet grasslands show more pronounced changes. While in some cases the main causes for the altered vegetation are few and clear, in other cases the driving factors are manifold and difficult to disentangle, as processes like fertilization, nitrogen deposition, acidification, recovery from acidification, more intensive management or land use abandonment may interact in their effects on the plant community.
Martin Diekmann obtained his PhD at the University of Uppsala, Sweden, and since 2001 has been a professor at the University of Bremen, Germany. His main interests in vegetation science include vegetation-environment relationships, broad-scale geographic gradients in species niches and richness, time-series analysis and conservation biology, with a particular focus on forest and grassland ecosystems. Since 2003 he has served on Council in the International Association for Vegetation Science (IAVS), and after some years as Publications Officer of the Association he was elected as President of IAVS in 2011. His presidentship ended in 2019, after which he has continued his service in the Governing Board of IAVS. He is an enthusiastic mountain walker, likes sports and is keen on bird watching.

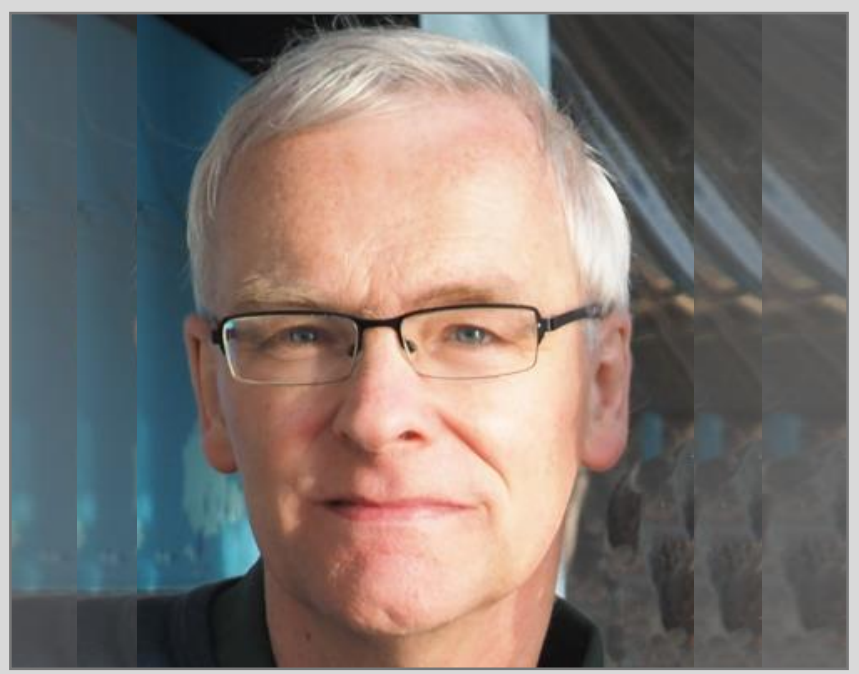




\section{Linking plants and pollinators: a story of local dis- turbance events and anthropized landscapes.}

\section{Paolo Biella 14th December 2021}

Grasslands and landscapes are essential scenarios where pollinators visit flowers, reproduce and survive. However, disturbance events can alter the way plants and pollinators interact with each other. At the local scale, not all flowers are equally visited by pollinators, and losing the subset of the most visited plants can determine the fate of the entangled network of interactions with flower visitors. At the big scale, landscape alteration can impoverish pollinator and plant assemblages. In this talk, I will present recent manipulative studies showing what happens to the pollinators when the plant community is suddenly impoverished. In this context, severe alterations of grassland plant composition can impact the amount of pollinators and even the pollinator efficiency, in ways that are difficult to predict. However, aspects like flower morphology and the amount of nectar resources can determine the fate of the interactions between plants and pollinators and the reorganization possibilities. At the landscape level, I will show how the increase of urbanization and the progressive fragmentation of green-areas can shape the entangled relationships between plants and pollinators. Understanding how the plant scenario and the landscape contribute to the bank of interactions with pollinators is very important to maintain biodiversity and even for inspiring conservation and restoration strategies.

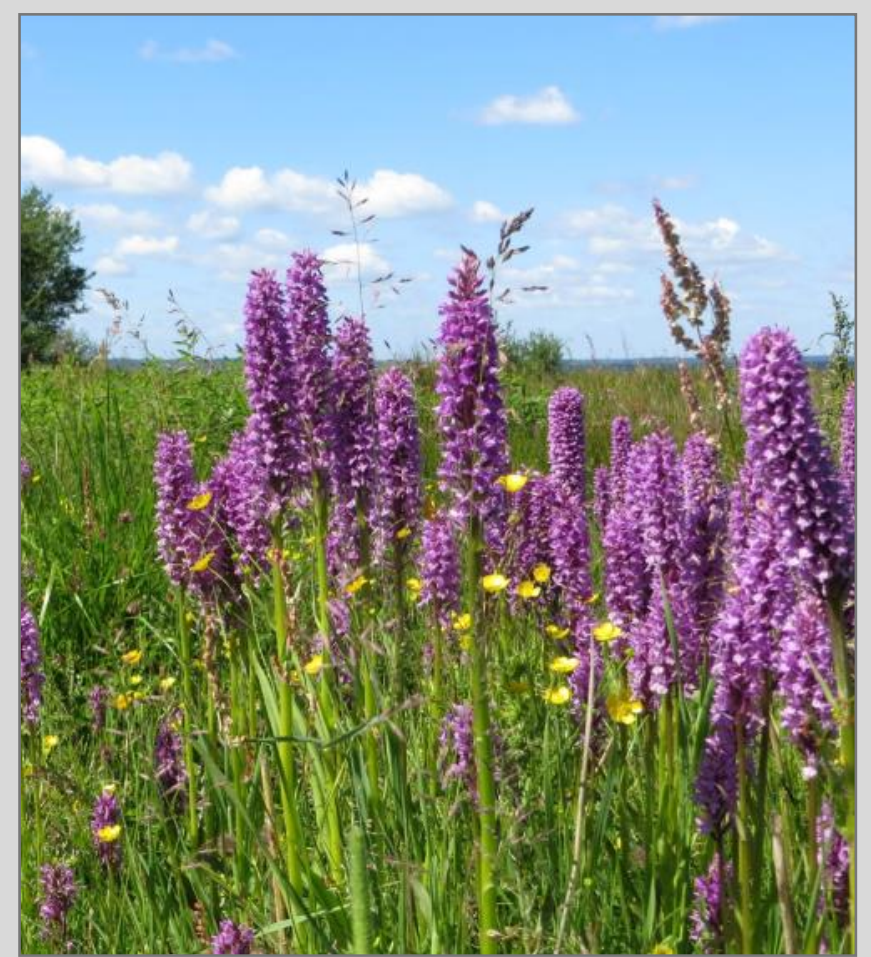

Paolo Biella, PhD, is currently Postdoctoral Researcher at the University of Milano-Bicocca, Department of Biotechnology and Biosciences, Milan, Italy. At that University, he is leading lecturer of the course 'Biogeography'. He holds wide scientific interests, that he pursue with high dedication. He is a specialist of ecological interactions, especially those between pollinators and plants that he studied at several levels: taxonomy of pollinators, reproductive biology of plants, nutritional ecology and plant-pollinator interaction networks. At the moment he is mainly focusing on the impact of anthropic or natural disturbance on the ecosystem services, and the side-effects on functional biodiversity and species interactions. He integrates innovative methodologies (DNA barcoding, phytochemistry, morphological analysis) with statistical modelling. He is also active in the field of species conservation, studying the pollination biology of endangered plants, and the effects of climate change on the ecology and distribution of some bee species. For instance, in 2018 he collaborated at the Red list of threatened Italian bees. Furthermore, he is involved in international research projects and in scientific research agreements. He presented his studies at international conferences and published several studies in specialized journals. He is the main organizer of an international conference (ABIM, Alpine Bombus International Meeting, 2016, 2018 and 2020 Editions). He is also active in popularization talks on scientific topics. Previously, he was research assistant at the University of Pavia in 2014 and at the Biology Centre in Ceske Budejovice (CZ) from 2014 to 2019. He has a personal website (https:// pbiella.wixsite.com/pbiella).

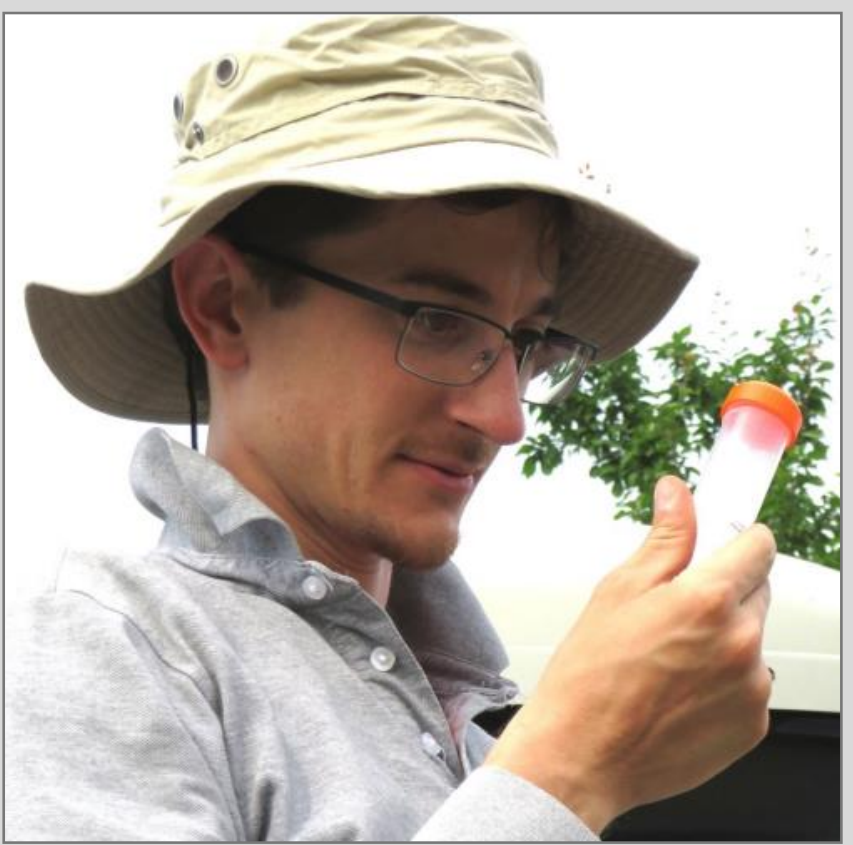




\section{Grasslands: the hidden part.}

\section{Jitka Klimešová 11th January 2022}

Vegetation scientists generally assume that the belowground parts of plant communities mirror the aboveground parts and thus all important community responses and functions can be assessed solely by the examination of a community from above. However, this concept is not viable when we also look at a plant community from below. First, we can see that in herbaceous communities, green shoots are annual, while the longevity of roots, rhizomes, and bulbs can range from one season to decades. We can also see that presumably independent aboveground individuals are connected. The relative dominance of species assessed according to the area of cover of green shoots may not be equal to dominance according to the area or biomass of belowground organs. Biomass of belowground organs may exceed biomass of aboveground organs several times. Aboveground plant traits can be easy to measure but belowground traits are often better at responding to environmental gradients. This leads us to question whether we can ignore the belowground plant parts of our communities. I will try to show what we know about belowground organs of grassland communities and where are the gaps that we need to focus our future stud-

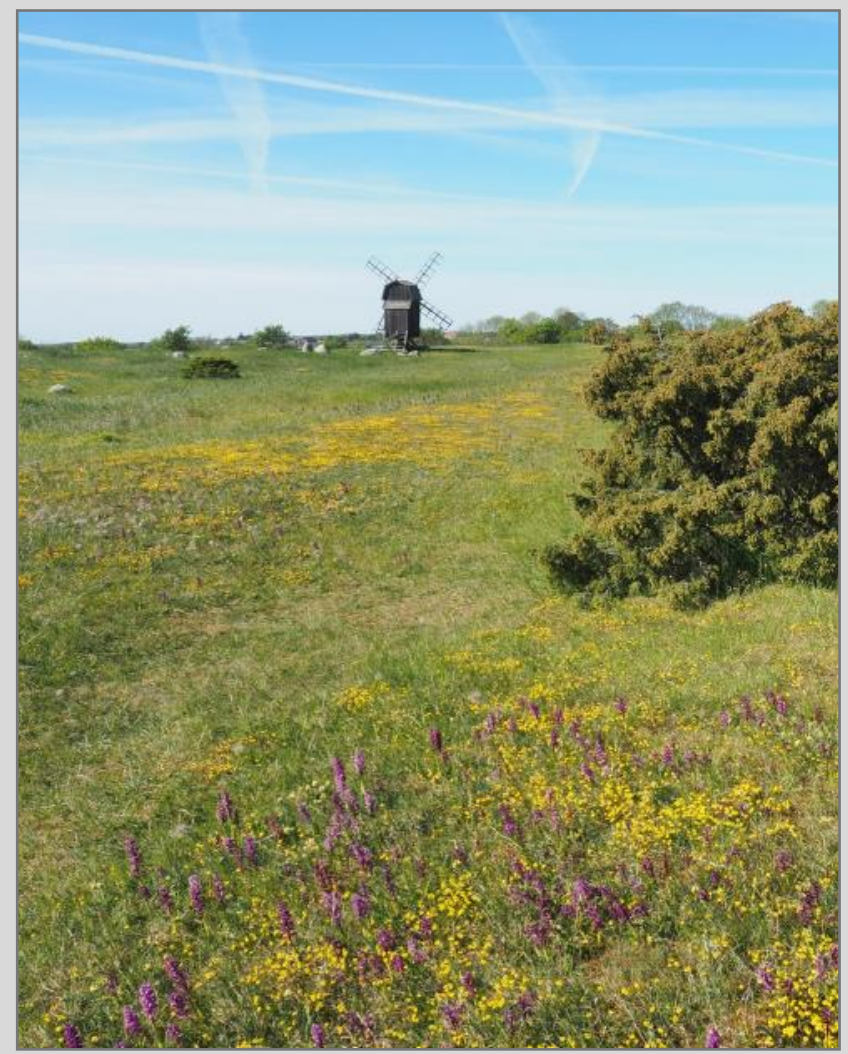
ies.

Jitka Klimešová obtained her PhD in 1993 at the Institute of Botany of the Czechoslovak Academy of Sciences in Třeboň, where she is now Professor and Head of Section. Her main interest is plant functional morphology - she wants to know what is the function of such morphological traits as height, shoot cyclicity, adventitious sprouting from roots etc. in daily plant life and how plant ecological functions are constrained by morphology and architecture. As Central Europe is especially rich in herbaceous plants, her focus lays primarily on them. A prerequisite for her work is knowledge of plant architecture, ontogeny and morphology. She gets a lot of information from older literature, published since the mid nineteen century in Germany and later on in other European countries, and collects plants in the field over the central and northwest Europe, studies their growth, draws them and stores information in databases (CLO-PLA 3, LEDA). This screening has enabled her to map which plant architectural traits are overlooked and to focus her research on them. Her favourite questions, which are the main motivation of her current projects are: What is the role of adventitious sprouting from roots in life history of a plant (Bud bank ecology); and What is the role of plant architecture in the coexistence of plants in species rich meadows (Functional traits of meadow species).

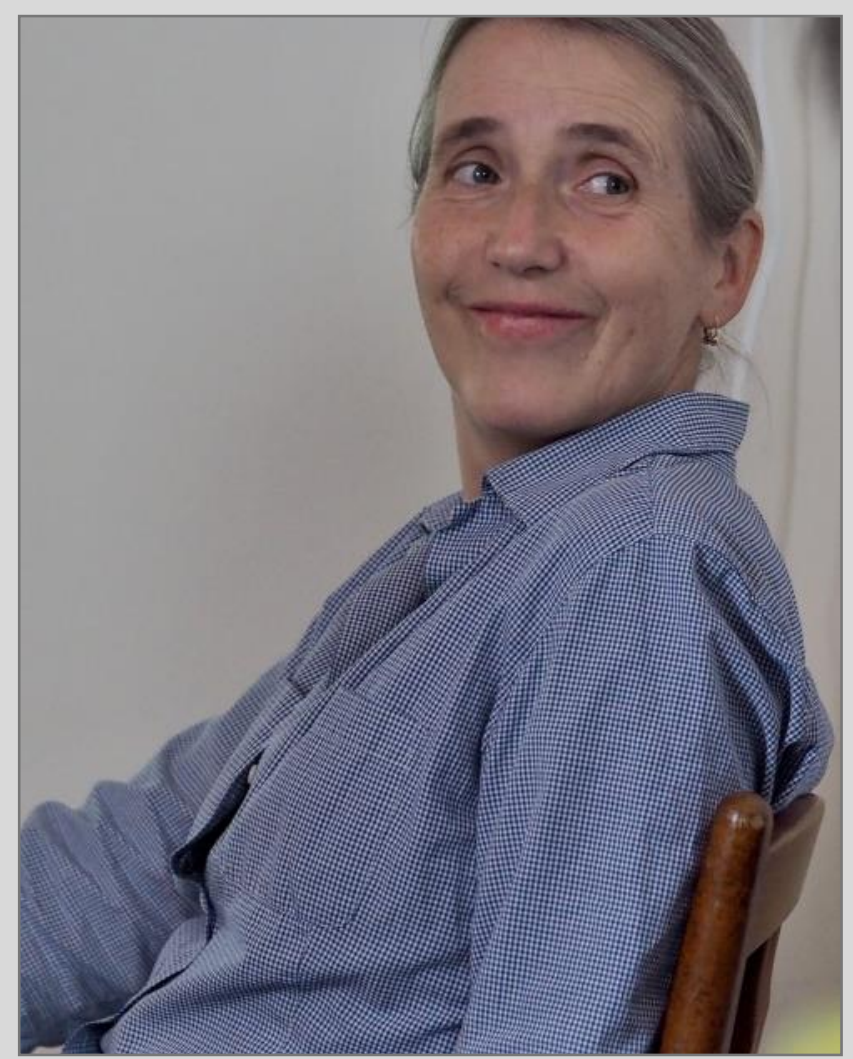




\section{EDGG Publications}

\section{Call to contribute to the Special Collection "Grasslands of Asia" in Vegetation Classification and Survey}

The Eurasian Dry Grassland Group invites contributions to a Special Collection "Grasslands of Asia" in the journal Vegetation Classification and Survey.

\section{Editors}

Jürgen Dengler (Switzerland), Alireza Naqinezhad (Iran) \& Arkadiusz Nowak (Poland)

\section{Outline}

Asia is the largest continent on Earth, but also the continent with the most extensive grasslands. Enigmatic are the huge and diverse steppes in the interior of the continent, but there are also arctic grass tundras, alpine grasslands, alpine steppes, desertic steppes, subtropical savannas and a multitude of semi-natural grasslands created by millennia of human land use. Classification is an essential approach to make the huge diversity of different grassland types better accessible and comparable, both for basic research and applied sciences such as management and conservation. However, only few countries in Asia have a strong tradition in grassland classification. Moreover, the classification approaches vary strongly between and even within countries. Thus, it is currently hard to achieve a consistent scientific overview on the grassland types of Asia.

Thus on the occasion of the first Asian Grassland Conference 22-24 February 2022 (AGC; https://edgg.org/AGC), the Eurasian Dry Grassland Group (EDGG; https://edgg.org/) and the gold open access journal Vegetation Classification and Survey (VCS; https://vcs.pensoft.net/) would like to launch a Special Collection of articles dealing with "Grasslands of Asia" with a typological view. In agreement with the scope of the journal, papers should develop, test or apply vegetation typologies or present vegetation-plot databases or tools in ecoinformatics. Typological approaches at any spatial scale from synusiae via phytocoenoses and landscapes to biomes are welcome. We are open to any approach to classify vegetation, including but not limited to the Braun-Blanquet approach and the EcoVeg approach. We particularly encourage studies based on extensive original data, but accept also regional and even local studies if they come from underrepresented regions or are methodologically innovative. Contributions presented at the AGC are particularly welcome, but also papers not related to the $A G C$ are possible.

\section{Procedure and deadlines}

- 31/10/2021: Publication of the call

- Until 28/02/2022: Submission of (preliminary) abstracts (maximum 300 words, structured into "Question(s)", "Study area", "Methods", "Results" and "Conclusions") to dr.juergen.dengler@gmail.com

- Until 31/03/2022: submitted abstracts will be evaluated continuously and manuscripts either invited or declined

- Until 30/09/2022: submission of papers (with prevalence to invited papers, while also non-invited manuscripts might be considered on a one-by-one basis)

- Manuscripts will undergo peer-review and be published on a one-by-one basis once accepted

- We anticipate that we will conclude the whole Special Collection in the first half of 2023

Please note that Vegetation Classification and Survey is a gold open access journal, which normally requests article processing charges (APCs) from authors. Thanks to the generous support of the IAVS (www.iavs.org), articles submitted until the end of 2022 are exempt from APCs, provided that the first author is an IAVS member, while membership is free of charge for scientists from many Asian countries.

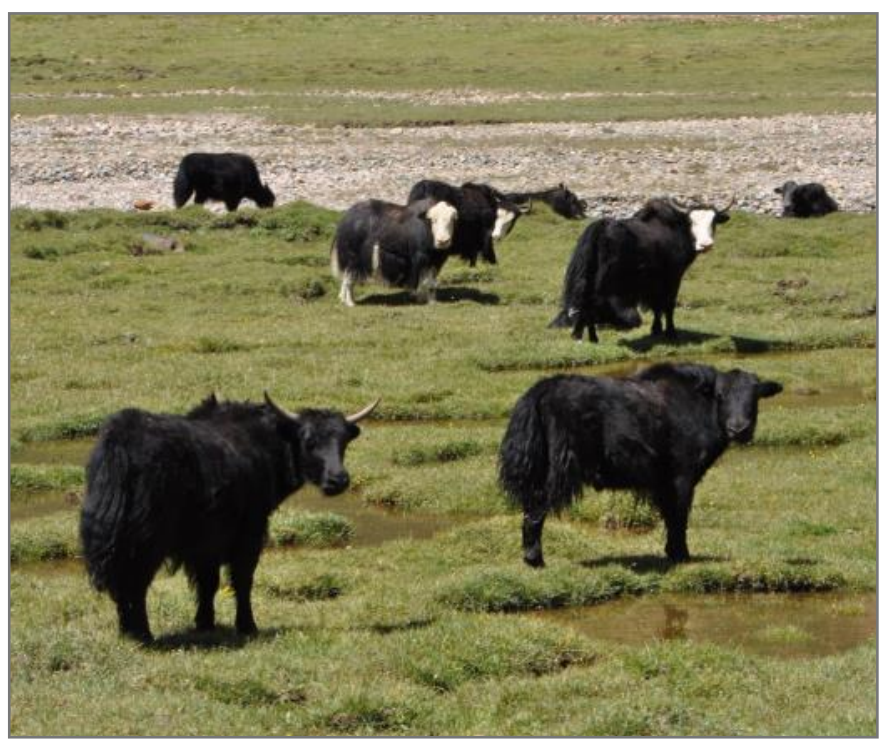

Yaks in Obikhingou Valley, Tajikistan. Photo: A. Nowak. 


\section{EDGG Publications}

\section{Call for the new EDGG-edited Special Feature in Hacquetia 7th EDGG Special Feature in Hacquetia 2023: Fauna, flora, vegetation and conservation of Asian grasslands}

This is the first call for the submission of manuscripts for the EDGG-edited Special Feature in Hacquetia 2023. This Special Feature will be dedicated to papers dealing with Asian grasslands. We welcome manuscripts about natural and seminatural grasslands, on all taxa and from any region in Asia. Both original research papers and review papers focusing on topics such as ecology, botany, zoology, conservation biology, restoration ecology, taxonomy, syntaxonomy, ethnoecology and rangeland management of Asian grasslands are welcome. Presenters at the Asian Grassland Conference are especially welcome to submit papers related to their presentations, but the SF is open not only to participants of the AGC, but to any scientist dealing with grasslands in Asia.

Hacquetia is the international journal of the Biological Branch of the Slovenian Academy of Sciences. It publishes two issues per year, both in print and online. Its offering of longer articles, diamond open access publication and free reproduction of colour figures make it a very attractive publication venue. Currently it is indexed in the Scopus and BIOSIS literature databases, and it is likely to be included in the Web of Science in the near future (aided by our very international and high-quality Special Issues and your citations of these).

This Special Feature will be the 7th EDGG-edited article collection which has appeared in Hacquetia, following the six successful predecessors in 2014/1, 2015/1, 2016/2, 2018/1, 2019/2 and 2021/1. This Special Feature will appear as the first issue of 2023, to be published approximately in January 2023, with about 150-250 pages reserved for our articles.

\section{Procedure and deadlines}

If you plan to contribute, you are invited to send an abstract prior to manuscript submission to the Chair of Guest Editors, Orsolya Valkó, until 28 February 2022. Based on the submitted abstracts, the guest editor team will decide which papers to invite and will inform the authors by $\mathbf{1 0}$ March 2022.

The deadline for full-text submission is $\mathbf{3 0}$ April 2022. If you are interested in contributing a manuscript for this comprehensive Special Feature, please contact the chief of the guest editor team (Orsolya Valkó, valkoorsi@gmail.com) and submit your manuscript directly to her. Manuscripts will be checked by the editorial board and suitable manuscripts will undergo the normal peer-review process. For detailed author guidelines, please consult the earlier issues of the Journal or contact the chief of the guest editors directly.

Guest Editor Team:

Orsolya Valkó, Hungary

Yun Jäschke, Germany

Alireza Naqinezhad, Iran

Rocco Labadessa, Italy

Stephen Venn, Finland

Contact for questions and submission of manuscripts (Chair of the Guest Editors): Orsolya Valkó (valkoorsi@gmail.com)

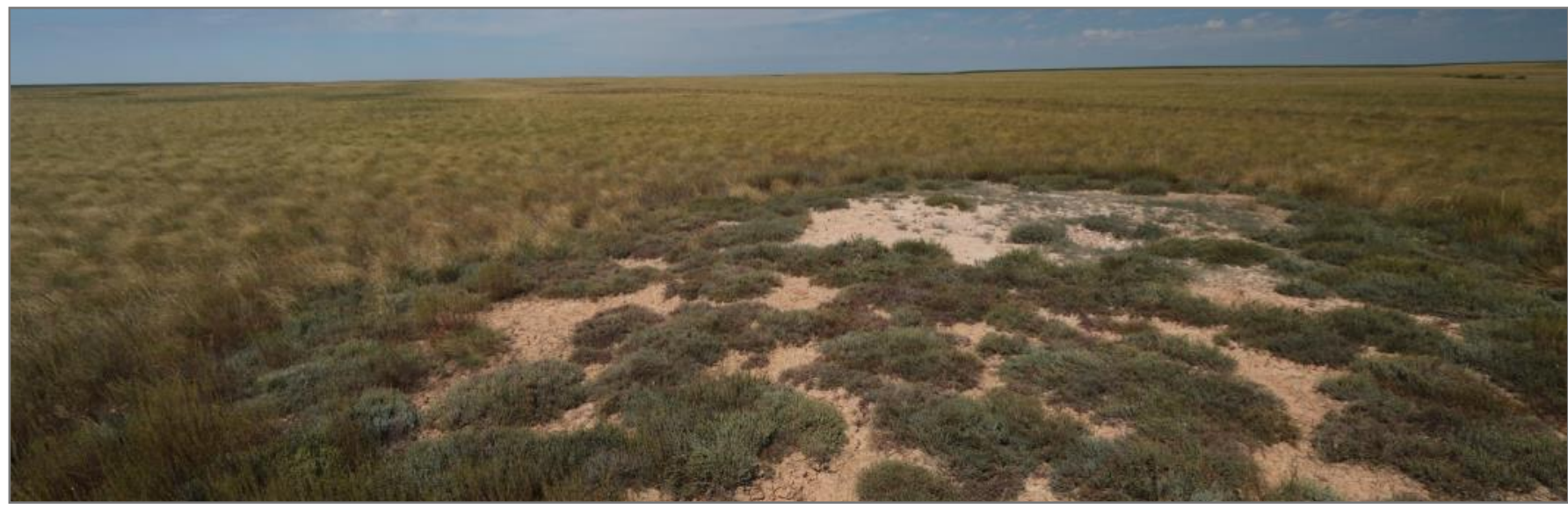

Dry steppe in Kazakhstan. Photo: B. Deák. 


\section{EDGG Publications}

\section{Call for the 17th EDGG-edited Grassland Special Feature in Tuexenia}

In 2022, the Eurasian Dry Grassland Group continues a long tradition of grassland-related publications and will organize the 17th Grassland Special Feature in Tuexenia (www.tuexenia.de).

Tuexenia is a diamond open access, peer-reviewed journal publishing original articles, reviews, and reports. The wellcited annual EDGG Special Feature is open to grasslandrelated topics with a focus on geobotany, vegetation ecology and related sciences, such as population biology, biodiversity research, biocenology, restoration ecology, and their applications, particularly in grassland conservation. We further welcome studies involving interactions of plants with other taxa such as animals and fungi.

The geographic scope of the Special Feature comprises the whole nemoral zonobiome (also called temperate midlatitudes) in Europe, including its transitions to neighboring zonobiomes (submediterranean, hemiboreal and foreststeppe zono-ecotones). Thus, the geographic scope ranges from Galicia in the west to the Urals in the East. However, contributions from the boreal, arctic, Mediterranean or continental (steppic) zonobiomes are also potentially considered after prior consultation with the Editors, and if a connection to Central Europe is made.

The syntaxonomic scope comprises all types of natural and semi-natural grasslands (mesic, wet, dry, saline, sandy, rocky, alpine). However, we may also consider vegetation types dominated by bryophytes, lichens, forbs and dwarf shrubs, e.g. tall forb communities and heathlands.
If you plan to contribute, you are invited to send the manuscript to the Chair of Guest Editors, Steffen Boch until 31 March 2022. Early submitted manuscripts have a higher chance of inclusion in the next Special Feature 2022. Later submission is only possible after prior consultation with Steffen Boch. Submissions that are accepted after the production deadline will be made available as online first version via the journal homepage (www.tuexenia.de), ensuring user access to the article before print publication. These articles are searchable and citable by their DOI (Digital Object Identifier).

Benefits of submitting to our Special Feature in Tuexenia include:

- Open access and peer-reviewed journal indexed in the Web of Science (Impact Factor 2020: 0.744).

- Significantly higher citation rates than regular Tuexenia articles (Tuexenia 39(2019): 5.9x, 38(2018): 2.2×, 37 (2017): 1.8x, 36(2016): 3.2x, 35(2015): 2.5x; based on a Web of Science query on 28 January 2021).

- No color and page charges.

- Competent Guest Editor Team: Steffen Boch (chair, Switzerland), Thomas Becker (Germany), Balázs Deák (Hungary), Jürgen Dengler (Switzerland), Kristin Ludewig (Germany), Sonja Škornik (Slovenia).

Steffen Boch, Birmensdorf, Switzerland, also on behalf of the Guest Editor Team steffen.boch@wsl.ch

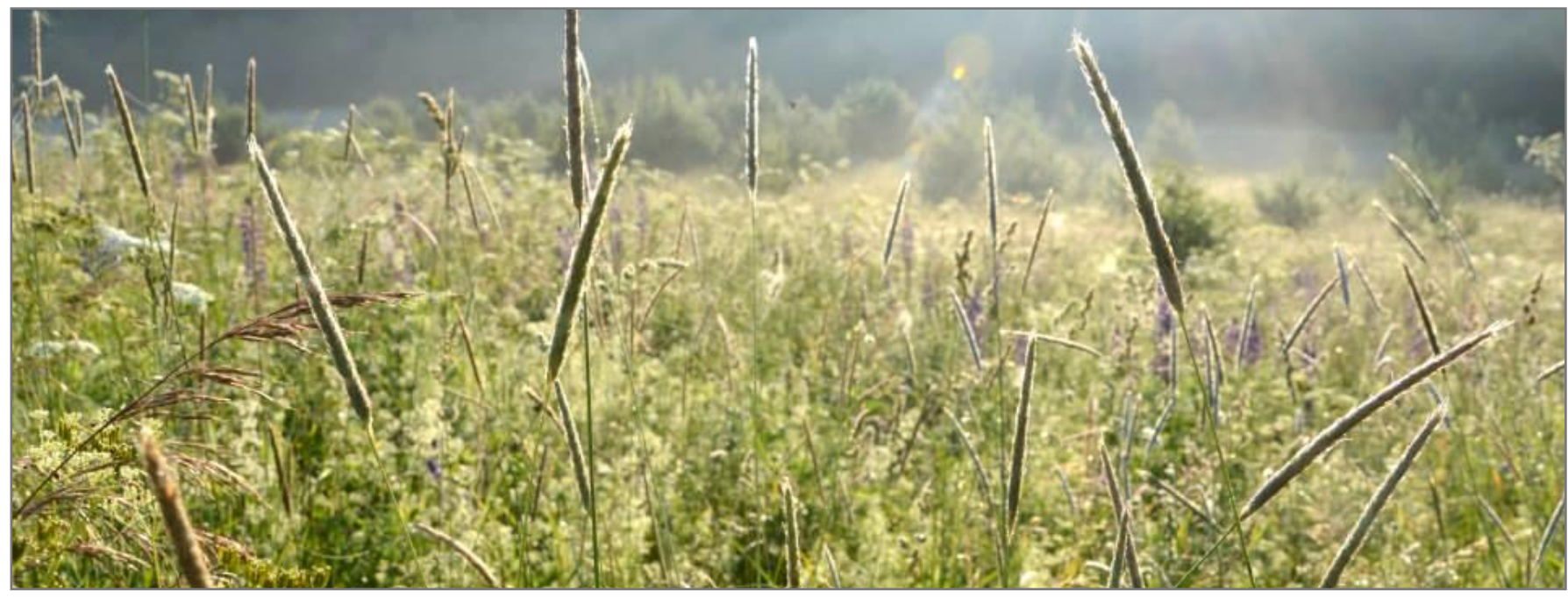




\section{Announcements}

\section{Call to contribute to the Special Collection "African vegetation studies" in Vegetation Classification and Survey}

The African Regional Section of the International Association for Vegetation Science (IAVS) invites contributions to a Special Collection "Africa vegetation studies" in the journal Vegetation Classification and Survey. This specifically also includes grasslands and similar vegetation types in Northern Africa, which are part of the scope of EDGG, too.

\section{Editors}

Reginald Tang Guuroh (Ghana), Miguel Alvarez (Germany, working in Eastern Africa), Leslie Brown (South Africa), Manfred Finckh (Germany, working in Angola and Morocco), Ute Schmiedel (Germany, working in Southern Africa), Gaolathe Tsheboeng (Botswana), Jürgen Dengler (representative of the Chief Editors).

\section{Outline}

At the beginning of the 19th century, the African continent was mostly pristine and roaming with wildlife without boundaries. As the human population increased, pressure has been put on the natural resources available. However, Africa still has large areas with near-natural vegetation and wildlife left. The continent has a large diversity of plant and animal life with several biodiversity hotspots. In addition, the African continent has, in the Congo basin, the largest remaining extension of continuous tropical rainforest glo- bally. Africa is part of three floristic regions (Palaeotropis, Palaearctic and Capensis), adding to the high diversity of the continent.

The rapid population growth and consequent land use changes make the African continent a hotspot of change urgently requiring more research. There is still a narrow window of opportunity to collect more baseline biodiversity data on natural and near natural vegetation as well as to monitor the long-term changes as a result of anthropogenic activities and climate change. It is therefore of crucial importance to conduct research on African vegetation and to publish the results internationally to assist in bridging the data and knowledge gaps that currently exist.

Scientific publications are a key part of every researcher's work. However, vegetation surveys and synecological research from Africa are currently underrepresented in scientific literature, resulting in inadequate knowledge and data on the continent. Additionally, even when research is conducted by African researchers, their research outputs are currently grossly underrepresented in the international scientific space, both at conferences and in scientific publications. As a result, a lot of data is lost to the broader scientific community as it remains unpublished.

This Special Collection in Vegetation Classification and Survey will focus on distribution patterns of natural vegetation

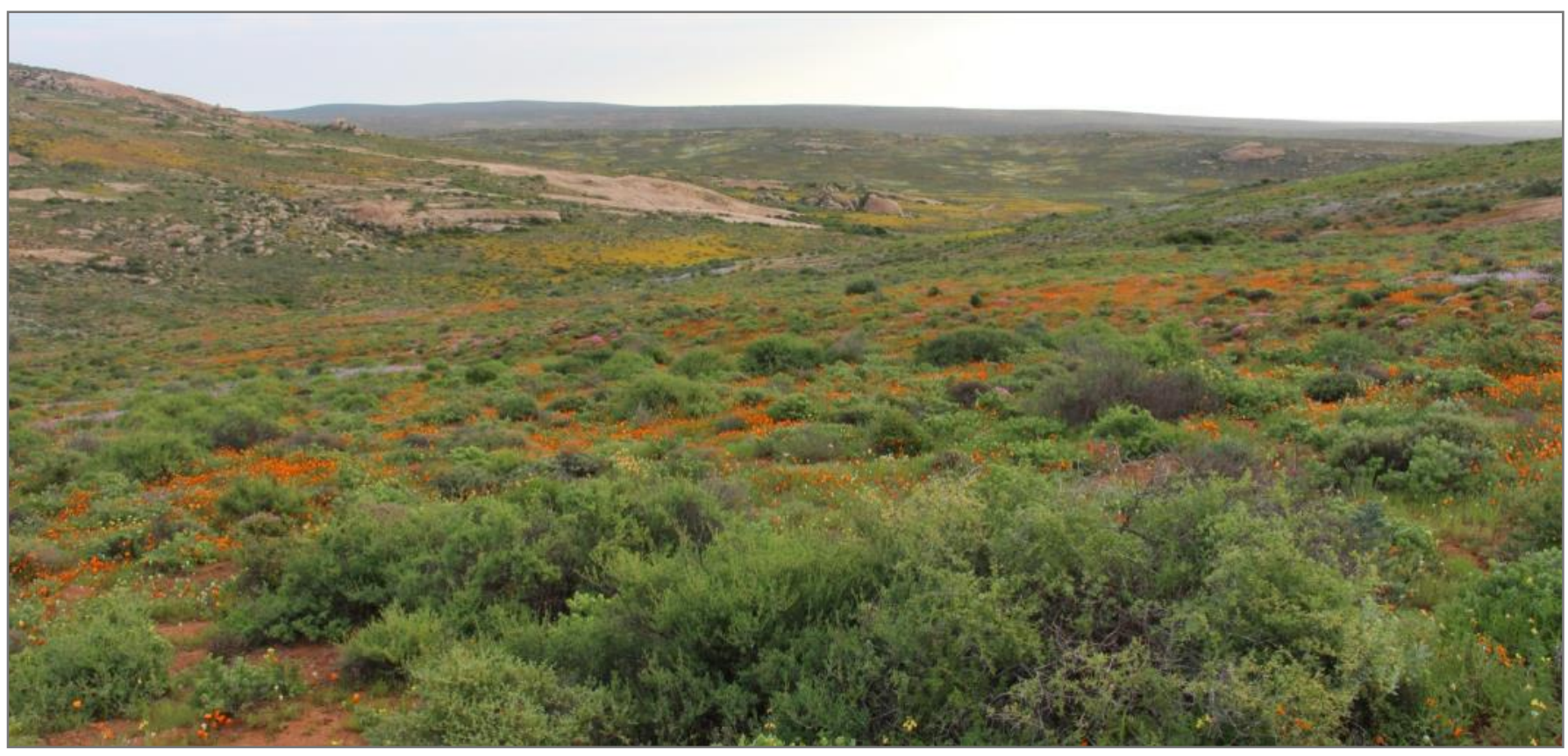


as well as the dynamics resulting from the increasing human impact. In agreement with the scope of the journal, papers should develop, test or apply vegetation typologies or present vegetation-plot databases or tools in ecoinformatics.

Typological approaches at any spatial scale from synusiae via phytocoenoses and landscapes to biomes are possible. Particularly suitable are the following topics:

\section{Current vegetation patterns}

- Classification

- Gradient analysis of vegetation patterns

- Biogeography of vegetation

- Remote sensing of vegetation patterns

\section{Ecoinformatics}

- Vegetation-plot databases

- Methods and programs in ecoinformatics

Typological perspective on vegetation change

- Land cover change

- Dynamics of phytocoenoses

- Vegetation typologies as conservation tool

\section{Procedure and deadlines}

- 22/09/2021: First announcement at the 2021 IAVS symposium

- 20/10/2021: Publishing of call

- 30/01/2022: Submission of abstracts

- 28/02/2022: Feedback to authors on acceptance of abstracts/ proposals

- 30/06/2022: Submission of invited manuscripts

- Manuscripts will undergo peer-review and be published on a one-by-one basis once accepted

- We anticipate that we will conclude the whole Special Collection in the first half of 2023

Please note that Vegetation Classification and Survey is an gold open access journal, which normally requests article processing charges (APCs) from authors. Thanks to the generous support of the IAVS (www.iavs.org), articles submitted until the end of 2022 are exempt from APCs, provided the first author is an IAVS member, while membership is free of charge for scientists from most African countries.
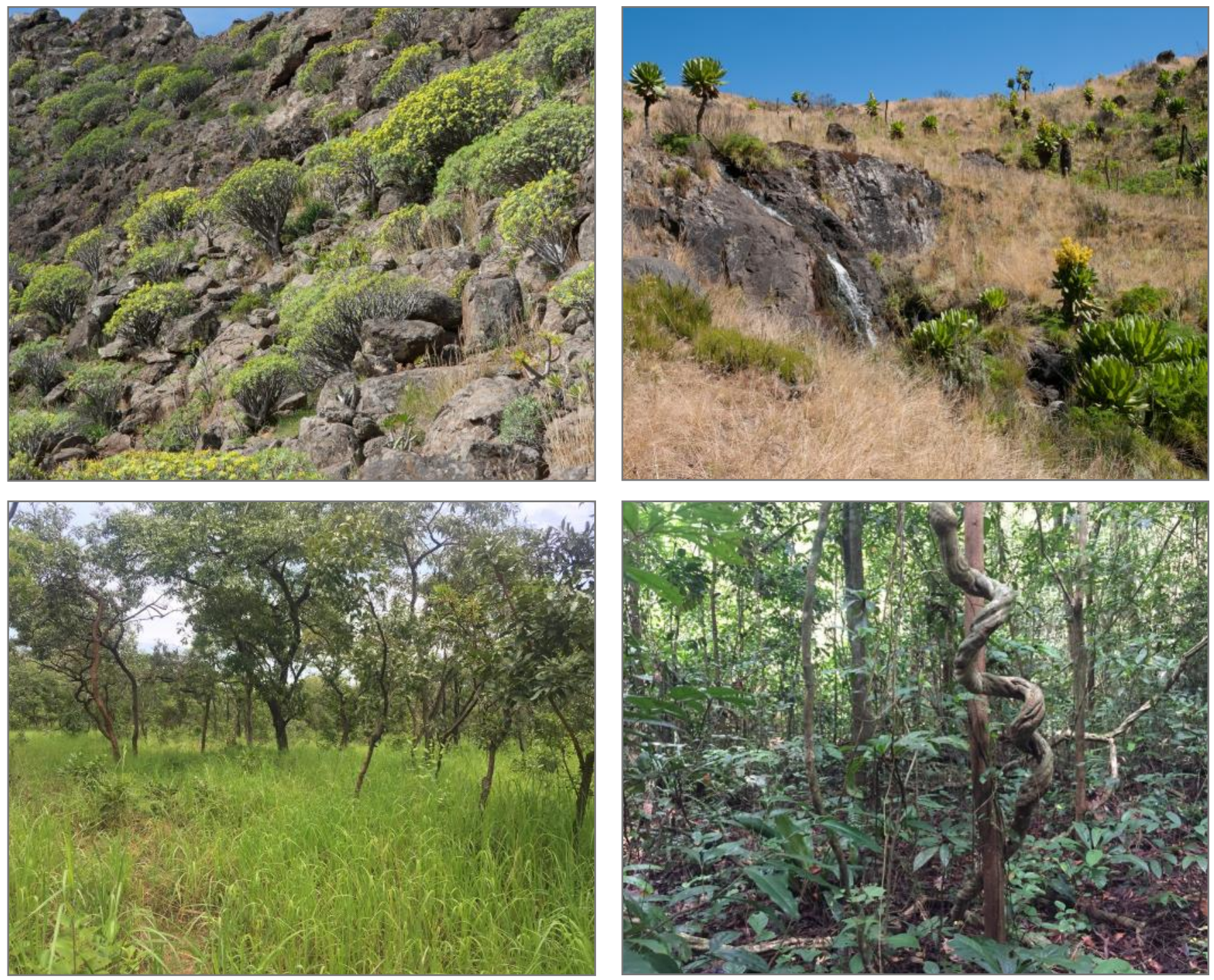


\title{
A review of policy frameworks supporting mountain grasslands in Europe
}

\author{
Maria Carla Lostrangio ${ }^{1^{*}} \&$ Marie $_{\text {Clotteau }}{ }^{1}$
}

${ }^{1}$ European Association of Mountain Areas, place du Champ de Mars 2, 1050 Bruxelles, Belgium; carla.lostrangio@euromontana.org (M.C. Lostrangio), marie.clotteau@euromontana.org (M. Clotteau)

*) Corresponding author

Palaearctic Grasslands 51 (2021): 17-22

Abstract: In the EU-28, grasslands are the third most dominant ecosystem (15.9\% of the total surface) and they deliver numerous environmental and social beneficial outcomes and public goods. Mountain grasslands are particularly important as they make up more than half of Europe's High Nature Value farmland and are associated with a high diversity of species. Yet, in the past decades, multiple trends, such as land abandonment, intensification, afforestation and conversion to other land-use types, have led to the impoverishment and deterioration of mountain grasslands. Several studies state the importance of grassland preservation to maintain its associated benefits and to support rural livelihoods in mountain areas. Nevertheless, there is little understanding of policies and measures that contribute to achieving the conservation objectives of this habitat. This report analyses the existing policy frameworks and measures that support the preservation of mountain grasslands, with a focus on the European policy framework and the national frameworks from four European countries (France, Italy, Romania, Spain). Based on the conclusions from this research, we derive recommendations for the improvement of policy frameworks to support mountain grasslands and pastoral activities.

Keywords: mountain grassland; conservation; policy framework; European policy; national policy; recommendation.

Abbreviations: ANC $=$ Area of Natural or other specific Constraints; CAP = Common Agricultural Policy; EAFRD = European Agricultural Fund for Rural Development; EC = European Commission; EEA = European Environment Agency; ERDF = European Regional Development Fund; ESF = European Social Fund; EU = European Union; HNV = High Natural Value.

Submitted: 3 September 2021; first decision: 12 October 2021; accepted: 18 October 2021

Scientific Editor: Laura Sutcliffe

\section{Mountain grasslands: a habitat in danger}

In the EU-28, grasslands are the third most dominant ecosystem, and they cover $15.9 \%$ of the total surface (EC 2016). Grasslands are particularly relevant in mountain areas as they provide feed for both wild and domesticated herbivores, and, via grassland-based extensive livestock, support a significant number of public goods such as rural viability, agricultural employment, soil functionality, local ecological knowledge, and spiritual and aesthetic value (Plantureux et al. 2016; Maréchal \& Baldock 2017; Manzano-Baena \& Salguero-Herrera 2018). In particular, mountain grasslands host more than half of Europe's High Nature Value (HNV) farmland and are associated with a high diversity of species (EEA 2019, 2020). Pictures illustrating few examples of grazed mountain areas and extensive livestock considered in this article are presented in Fig. 1.

Yet, over the past decades, several trends such as land abandonment, intensification, afforestation and conversion to other land-use types have led to substantial losses of this habitat (Peeters 2008; EC 2016). In the $20^{\text {th }}$ century, approximately $90 \%$ of semi-natural grasslands in European countries have disappeared due to intensification or aban- donment, and populations of many of their species decreased or became extinct (EC 2016). Today, grasslands are one of the habitats with the worst conservation status (more than $75 \%$ have an unfavourable conservation status in the EU), and the trends are particularly negative in the Atlantic, Boreal and Continental biogeographical regions (EEA 2020).

Several studies explore the importance of conserving mountain grasslands because of their ecosystem services and to keep the liveability of mountain areas (e.g. Bunce et al. 2004; European Grassland Federation 2011; Plantureux et al. 2016; Seid et al. 2016). Nevertheless, there is a little understanding of what policies and measures can stir the conservation of this habitat. Policy frameworks can contribute to this objective, for instance by encouraging pastoral practices and low intensity agriculture, which are the main activities for the maintenance of this habitat in mountainous areas (Galvánek \& Leps 2008; Metera et al. 2010; Committee of the Regions 2019). The OREKA MENDIAN report analyses those policies that have been designed by European authorities and by national authorities in four European countries (France, Italy, Romania, Spain), to revert the declining trends of grasslands in mountains. 

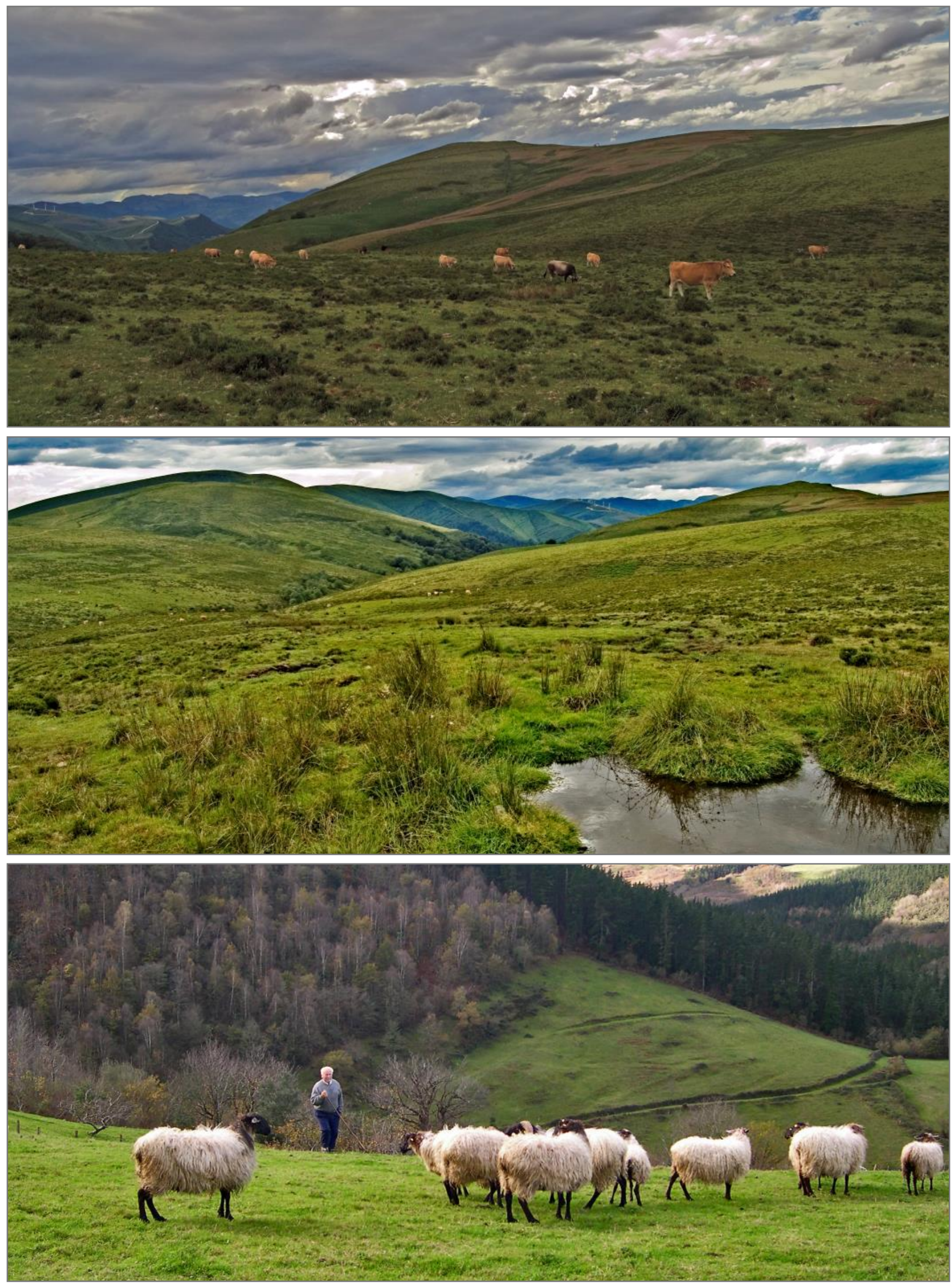

Fig. 1. Examples of grazed mountain areas in the Basque Mountains, Spain. OLIFE OREKA MENDIAN. 


\section{Methodology}

To elaborate the current article, we used a mixture of desk research and consultations with a total of 21 European and national experts. For the analysis of the European policy framework, the review of past regulatory frameworks, research and position papers on the impacts of European policies on mountain grasslands was analysed. Furthermore, our participation in the Civil Dialogue Groups on the Common Agricultural Policy (CAP) was also relevant to gather information on the future impacts of European policies on mountain grasslands. For the national policy frameworks, desk research and consultation with expert members from
Euromontana's network have served to investigate the specificities of national policy frameworks in selected countries. Countries have been chosen based on: i) the presence of mountain areas; ii) the existence of specific policies to support mountain areas and/or more specifically grasslands; iii) the presence of Euromontana's members to have direct contacts with relevant experts. A total of four Member States of the European Union (France, Italy, Spain, Romania) are investigated in this article.

The policy frameworks presented and discussed in this article are summarised in Table 1.

Table 1. European and national policy frameworks presented in this article.

\begin{tabular}{|c|c|c|c|}
\hline Level & Country & Policy framework & Main measures to support mountain grasslands \\
\hline \multirow{3}{*}{ 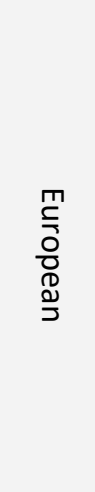 } & \multirow[t]{3}{*}{$\begin{array}{l}\text { All EU } \\
\text { Member } \\
\text { States }\end{array}$} & $\begin{array}{l}\text { Common Agricultural Policy } \\
(2014-2020 ; 2021-2022)\end{array}$ & $\begin{array}{l}\text { - Pillar I: basic payments, greening payments, Areas of Natural or } \\
\text { other specific Constraints (ANC) payments and coupled support } \\
\text { - Pillar II: ANC support, agri-environment-climate payments and qual- } \\
\text { ity schemes for agri-food products }\end{array}$ \\
\hline & & $\begin{array}{l}\text { Common Agricultural Policy } \\
(2023-2027)\end{array}$ & $\begin{array}{l}\text { In additional to measures in the CAP 2014-2020: } \\
\text { - Eco-schemes }\end{array}$ \\
\hline & & EU Biodiversity Strategy 2030 & $\begin{array}{l}\text { - Habitats and Birds Directives } \\
\text { - LIFE programme }\end{array}$ \\
\hline \multirow{4}{*}{$\begin{array}{l}z \\
\stackrel{2}{\partial} \\
\text { ơ } \\
\stackrel{0}{\partial}\end{array}$} & France & $\begin{array}{l}\text { Loi Montagne I }\left(n^{\circ} 85-30\right) \\
\text { Loi Montagne II }\left(n^{\circ} 2016-1888\right) \\
\text { Loi Pastorale }\left(n^{\circ} 72-12\right)\end{array}$ & $\begin{array}{l}\text { - Specific support to agricultural and pastoral activities in mountains, } \\
\text { including financial support } \\
\text { - Decentralised governance system (National Mountain Council, dis- } \\
\text { tinct coordinating agencies in the different mountain massifs, the- } \\
\text { matic working groups) } \\
\text { - Three legal measures for collective management of grasslands } \\
\text { (pastureland associations, pastoral groups, multi-annual grazing } \\
\text { agreements) }\end{array}$ \\
\hline & Italy & $\begin{array}{l}\text { Strategia nazionale per } \\
\text { le aree interne }\end{array}$ & $\begin{array}{l}\text { - Multi-fund approach (EAFRD, ERDF, ESF, National Stability Fund) to } \\
\text { support local development projects } \\
\text { - Itinerant pastoralist schools }\end{array}$ \\
\hline & Romania & $\begin{array}{l}\text { Legea Muntelui } \\
\text { (no 197/2018) }\end{array}$ & $\begin{array}{l}\text { - Finance interventions to preserve mountain grasslands (e.g. com- } \\
\text { pensation to landowners located in mountain protected areas, sup- } \\
\text { port to livestock farmers) } \\
\text { - } € 1 \text { billion for the } 2018-2028 \text { dedicated to mountain areas }\end{array}$ \\
\hline & Spain & $\begin{array}{l}\text { Ley Orgánica } \\
\left(n^{\circ} 42 / 2007\right)\end{array}$ & $\begin{array}{l}\text { - Inventory and a Strategic Plan for Natural Heritage and Biodiversity } \\
\text { - Management Plans for Natura } 2000 \text { Network } \\
\text { - Recognition of "Mountains of Public Utility" }\end{array}$ \\
\hline
\end{tabular}




\section{European policy framework for mountain grasslands}

Up to date, the European Union (EU) does not have a distinct policy framework addressing the peculiarities of mountain areas and their development. Mountain areas, and the activities that occur in these territories, need to comply with general - often sectoral - frameworks such as laws and regulations on agricultural activities, biodiversity protection, food safety, land property and so forth. In this context, the most relevant EU policy framework offering support to mountain grasslands are the CAP, and the Biodiversity Strategy. In the CAP 2014-2020, different measures have been put into place to support mountain grasslands, such as basic payments, greening payments, ANC payments and coupled support in Pillar I; and ANC support, agri-environmentclimate payments and quality schemes for agri-food products in Pillar II (Euromontana 2014). From 2023, the CAP will also provide Member States with the opportunity to offer dedicated eco-schemes targeting grassland conservation as well as to implement more conditionality to environmental and climate standards to receive basic payments. Member States will be obliged to use at least $25 \%$ of their budget under the 1st Pillar to finance the eco-schemes. Ecoschemes supporting the management of mountain grasslands can contribute to achieve some of the nine objectives of the 2023-2027 CAP, such as the objectives on "Landscapes", "Climate change" and "Rural areas". For instance, as suggested by the European Commission (EC), ecoschemes could finance measures to support mixed species/ diverse sward of permanent grassland; to increase the access to pastures, as well as the grazing period for the livestock; to encourage transhumance and common grazing practices (EC 2021).

Launched in 2020, the EU Biodiversity Strategy for 2030 unlocked $€ 20$ billion/year for enhancing biodiversity across different habitats. This strategy defines that at least $30 \%$ of total EU land areas shall be protected (against 26\% in 2019), and $10 \%$ strictly protected (against $3 \%$ in 2019), and the EU shall restore degraded ecosystems (EC 2020). The definition of "strictly protected areas" is still unclear, and therefore also the consequences it may have on human activities for the maintenance of mountain grasslands, such as pastoralism. Furthermore, since 1992 the Habitats and Birds Directives provides the legal framework for the protection of habitats and species (including mountain grasslands) in the EU and the EU-funded LIFE programme provide funds for the implementation of the EU Biodiversity Strategy and the Directives (EC 2014a, 2014b). The LIFE programme has been fundamental to develop policies and structures to manage Natura 2000 sites across different habitats, including mountain grasslands (EC 2018).

The above-mentioned European policy frameworks set the objectives and guidelines to protect biodiversity, including mountain grasslands, across EU Member States. In addition to this, different EU countries developed their own policies and measures to support this habitat, as presented in the following paragraphs.

\section{France: a decentralised model for mountain govern- ance}

In January 1985, the French government adopted the Loi Montagne ( $\left.\mathrm{n}^{\circ} 85-30\right)$, and then updated in 2016 by the Loi Montagne II ( $\mathrm{n}^{\circ}$ 2016-1888). The Loi Montagne /I foresees specific support to mountain agricultural and pastoral activities, such as financial support for maintaining activities in ANC, combating shrub invasion in pasturelands, and reducing conflicts with large carnivores (Loi Montagne I/ 2016). Furthermore, the law establishes a National Mountain Council and distinct coordinating agencies in the different mountain massifs, that carry out managerial and consultation activities. These bodies have the merit of going beyond administrative boundaries to deliver strategies within a naturally defined perimeter (a mountain range) and to ensure the dialogue between civil society and policymakers. In some French massif, these agencies set up working groups on seasonal employment in summer/alpine pastures, land clearing, and the promotion of mountain products.

In addition to the mountain law, the Loi Pastorale $\mathrm{n}^{\circ} 72-12$ (French Pastoral Law of 1972) (Lorenzi 2013), still in force, officially establishes three legal measures for the collective management of mountain pasturelands: associations foncières pastorales (pastureland associations), that ensure the consistent management of these areas by regrouping the landowners of the livestock grazing areas; groupements pastoraux (pastoral groups), that promote the renewal of grazing and livestock management practices, and the collective development of mountain grasslands; and conventions pluriannuelles de pâturage (multi-annual grazing agreements), that establish the rights and duties of each party in the use of grazing land through contracts between farmers and landowners. The Loi Pastorale also established a compensation for farmers who contribute to land management in critical areas within defined mountain areas (Lorenzi 2013).

\section{Italy: a multi-fund approach for mountain develop- ment}

In Italy, the development of mountain areas is tackled by the Strategia nazionale per le aree interne (National Strategy for Inner Areas). This strategy aims at developing the preconditions for territorial development (i.e. ensure the availability of adequate goods/essential services) and supporting local development projects in areas that are remote, low populated and rich in natural and cultural resources (Lucatelli 2016) and that are often in mountain areas. To this end, the Strategy deploys a multi-fund approach based on EU funds (EAFRD, ERDF, ESF) and the National Stability Fund. These funds are deployed to invest in local development projects related to land access and management, diversification of the rural economy, local food products, and young farmers. Thus far, some of the projects financed by this strategy include the establishment of the scuole itineranti della pastorizia (itinerant pastoralist schools), initiatives to share knowledge and innovations, and to facilitate access to and the conservation of mountain pasturelands, or 
activities to finance the restoration of mountain grasslands (Forum Disuguaglianze Diversità 2018; IRPET 2018).

\section{Romania: an ambitious portfolio}

Since 2018, the Legea Muntelui (no 197/2018; Parliament of Romania 2018) regulates the inclusive and sustainable development in mountain areas of Romania. The Legea Muntelui officially recognises the disadvantages of mountain areas in agricultural development due to their altitude, climatic and geological specificities. Because of this, the law identifies some key interventions for the development of mountain grasslands and their management, such as:

- Financial compensation to landowners located in Natura 2000 sites, natural parks, national/biosphere reserves and other protected natural areas in mountain areas;

- Financial support to livestock farmers in mountain areas depending on the severity of natural handicaps and altitude, in addition to the CAP payments;

- Protection and development of mountain biodiversity, including HNV farming;

- Support to the cultural heritage of the mountain area.

As part of this law, over the 2018-2028 period the Romanian Government allocated $€ 1$ billion from the budget of the Ministry of Agriculture and Rural Development, in order to encourage the above-mentioned activities in mountain areas.

\section{Spain: an official recognition of social and environ- mental benefits}

In Spain, the Ley Orgánica $\left(n^{\circ} 42 / 2007\right)$ is the main legal framework for the conservation, sustainable use, improvement and restoration of natural heritage and biodiversity, including mountain grasslands. This law establishes supportive instruments such as an Inventory and a Strategic Plan for Natural Heritage and Biodiversity, as well as Management Plans for Natura 2000 Network sites. The Spanish law also emphasizes the ecological corridors in mountain areas and the need to improve livestock routes in mountain areas; to enhance the ecological coherence, functionality and connectivity of the Natura 2000 Network; and to establish a European and Community network of biological corridors.

In Spain, the Autonomous Communities, i.e. the first-level political and administrative divisions of the country, have the competence to manage the Natura 2000 network. Autonomous Communities are responsible for drafting and reaching agreements on the Management Plans and implement them. Additionally, the mention Montes de Utilidad Pública (Mountains of Public Utility) acknowledges different Natura 2000 sites in mountain areas, and it recognizes their practices as socially and economically beneficial for the society. These included the use of communal mountain pastures during the summer months, a use that has contributed for instance to the conservation of the Basque landscape and its consideration as habitats of community interest.

\section{Discussion and conclusions}

This article shows that at both European and country level, some policy frameworks and measures have been defined to promote the management of mountain grasslands. At European level, the legal framework addressing mountain areas is mainly related to agriculture and biodiversity conservation, whereas it falls short to adopt a more integrated approach with other relevant domains (e.g. labour, wellbeing, education). Furthermore, measures addressing specifically mountain areas are often derogations of the main legislation and do not always consider the specificities of mountain areas adequately.

Nonetheless, the analysis of country-specific legislation offers interesting models that could serve to improve the policy framework at European level and serve as good practices for other European countries. From the analysis of the four country-specific frameworks, we can conclude that the following measures should be supported and encouraged both at European level (via for instance a European Action Plan for Pastoralism) and in other EU countries (throughout national legislations/measures):

- Combine different financing sources to support pastoralism, grassland management and more broadly the socioeconomic development of mountains (1st pillar of the CAP, EAFRD, ERDF, ESF, national funds). These sources should finance innovation in all its forms (social and digital), making sure to make pastoralism is fit for the challenges of the 21st century, included climate change mitigation and adaptation;

- Promote multi-actor collaboration across farmers, land managers, authorities etc. via for instance shared multiannual and management plans, as well as adapted governance structure that have a geographical and territorial relevance (i.e. mountain perimeter) rather than an administrative one;

- Formally recognise the intrinsic links between pastoralism, cultural and natural heritage in mountains and support it with targeted activities in order to prevent the loss of this heritage throughout land abandonment and decline of pastoral practices;

- Estimate the economic value of ecosystem services provided by pastoralism in order to encourage a more appropriate assessment of the price of pastoral products and services and support the continuity of pastoral practices.

The above-recommended measures do not ensure the effectiveness of grassland management and pastoral practices by themselves. Even though an enabling political framework is a precondition to support the continuation of pastoral practices and grassland preservation, its actual effectiveness strongly depends on i) the capability to define a policy framework that does not follow a one-size-fits-all approach, but it is rather adapted to the specific assets and opportunities of the territory and its inhabitants; ii) the ability of local stakeholders to uptake this framework and develop innovative practices directly on their territory, entail- 
ing, for instance a better sharing and transfer of best practices. Both elements should not be underestimated in the interest of protecting mountain grasslands and supporting all practices related to their sustainable management.

Author contributions: Both authors equally planned and wrote the article.

Acknowledgements: We wish to acknowledge and thank the following interviewed experts who contributed to the OREKA MENDIAN report "Overview of sustainable practices for the management of mountain grasslands in Europe": Itziar Alberdi Bilbao, Giovanni Argenti, Mark Borthwick, Enrico Calvo, Tommaso Campedelli, Russ Carrington, Anne Castex, Camilla Dibari, Herbert Dorfmann, Thomas Egger, Dominique Fayel, Daniela Masotti, Marcello Miozzo, Michele Nori, Alain Peeters, Martin Price, Adrian Radu-Rey, Enrique Ramón, Jabier Ruiz, Andreas Schenk, Katharina Sparstad. This report received the funding of the EU'S LIFE programme, under the OREKA MENDIAN project (LIFE15 NAT/ES/000805).

\section{References}

Bunce, R.G.H., Pérez-Soba, M., Jongman, R.G.H., Gómez Sal, A., Herzog, G. \& Austad, I. (Eds.) 2004. Transhumance and biodiversity in European Mountains. Report of the EU-FP5 project TRANSHUMOUNT [EVK2-CT-2002-80017], IALE publication 1, Wageningen, NL.

Committee of the Regions 2019. Opinion on Pastoralism. Commission: NAT. CDR 145/2019. PDF

Euromontana 2014. A new CAP. Mountains of Opportunities. PDF

European Commission 2014a. Council Directive 2009/147/EC on the conservation of wild birds. URL: PDF

European Commission 2014b. Council Directive 92/43/EEC on the conservation of natural habitats and of wild fauna and flora. $\underline{\text { PDF }}$

European Commission 2016. Mapping and Assessment of Ecosystems and their Services - Mapping and assessing the condition of Europe's ecosystems: Progress and challenges - 3rd Report - Final. Technical report. PDF

European Commission 2018. LIFE improves Nature. DOI: $\underline{10.2779 / 75202}$

European Commission 2020. Communication from the Commission to the European Parliament, The Council, the European Economic and Social Committee and the Committee of the Regions. EU Biodiversity Strategy for 2030 Bringing nature back into our lives. $\operatorname{COM}(2020) 380$ final. PDF
European Commission 2021. List of potential agricultural practices that eco-schemes could support. PDF

European Environment Agency 2019. High nature value (HNV) farmland. PDF

European Environmental Agency 2020. The State of Nature. PDF

European Grassland Federation 2011. 16th EGF Symposium. Grassland farming and land management systems in mountainous regions. Grassland Science in Europe 16.

Forum Disuguaglianze Diversita 2018. Le scuole itineranti della pastorizia [Itinerant pastoralist schools]. PDF

Galvánek, D. \& Lepš, J. 2008. Changes of species richness pattern in mountain grasslands: Abandonment versus restoration. Biodiversity and Conservation 17: 3241-3253.

IRPET 2018. Valutazioni per la strategia territoriale. Gli interventi per le aree interne. [Evaluation for the territorial strategy. The interventions in inner areas]. PDF

Loi Montagne II 2016. LOI n²016-1888 du 28 décembre 2016 de modernisation, de développement et de protection des territoires de montagne. PDF

Lorenzi, F. 2013. Gestion foncière de type «bien commun» en montagne. Bilan de la loi pastorale. POUR 4(4): 127-134.

Lucatelli, S. 2016. A Strategy for "Inner Areas" in Italy. Fostering growth through Inner Areas development. PDF

Manzano-Baena, P. \& Salguero-Herrera, C. 2018. Mobile Pastoralism in the Mediterranean: Arguments and evidence for policy reform and to combat climate change. Mediterranean Consortium for Nature and Culture, Geneva, IT. PDF

Maréchal, A. \& Baldock, D. 2017. Key emerging findings from the PEGASUS project June 2017. PDF

Metera, E., Sakowski, T., Sloniewski, K. \& Romanowicz, B. 2010. Grazing as a tool to maintain biodiversity of grassland - a review. Animal Science Papers and Reports 28: 315-334.

Parliament of Romania. 2018. Law of the mountain/ LEGEA MUNTELUI nr.197/2018. PDF

Peeters, A. 2008. Challenges for grasslands, grassland-based systems and their production potential in Europe. Proceedings of the 22nd General Meeting of the European Grassland Federation, Uppsala, Sweden, 9-12 June: 9-24.

Plantureux, S., Bernués, A., Huguenin-Elie, O., Hovstad, K.A., Isselstein, J., McCracken, D., Therond, O. \& Vačkářů, D. 2016. Ecosystem service indicators for grasslands in relation to ecoclimatic regions and land use systems. Conference Paper: 26th General Meeting of the European Grassland Federation, At Trondheim, Norway Volume: 21.

Seid, M. Kuhn, N. \& Fikre, T. 2016. The role of pastoralism in regulating ecosystem services. Revue scientifique et technique (International Office of Epizootics) 35(2): 435-444. 


\title{
Grassland communities of the Mongolian Plateau
}

\author{
Photos and text by Frank Yonghong $\mathrm{Li}^{1}$, Tiejun $\mathrm{Bao}^{1}$, Liqing $\mathrm{Zhao}^{1}$, Wenhong $\mathrm{Ma}^{1}$ \& Jinghui Zhang ${ }^{1}$ \\ ${ }^{1}$ Ministry of Education Key Laboratory of Ecology and Resource Use of the Mongolian Plateau, School of Ecology and Environment, \\ Inner Mongolia, Hohhot 010021, China; e-mail: lifyhong@126.com
}

The Mongolian Plateau is the part of the Central Asian Plateau lying between $37^{\circ} 46^{\prime}-53^{\circ} 08^{\prime} \mathrm{N}$ and $87^{\circ} 40^{\prime}-122^{\circ} 15^{\prime} \mathrm{E}$ with an area of approximately $3,200,000$ square kilometers. It is bounded by the Greater Hinggan Mountains in the east, the Sayan and Khentii Mountains to the north, the Altai Mountains to the west, and the Yin Mountains to the south. It has an elevation of roughly 1,000 to 1,500 meters, with the lowest point in Hulunbuir and the highest point in Altai Mountains. The plateau includes mainly the entire territory of Mongolia, part of the Inner Mongolia and Xinjiang Autonomous Regions of China, and part of the Buryatia and the southern Irkutsk Oblast of Russia. The majority of the plateau is dryland, covered by deserts and steppes, though forests exist in mountainous areas in the northern and eastern parts, and wetlands are scattered here and there.

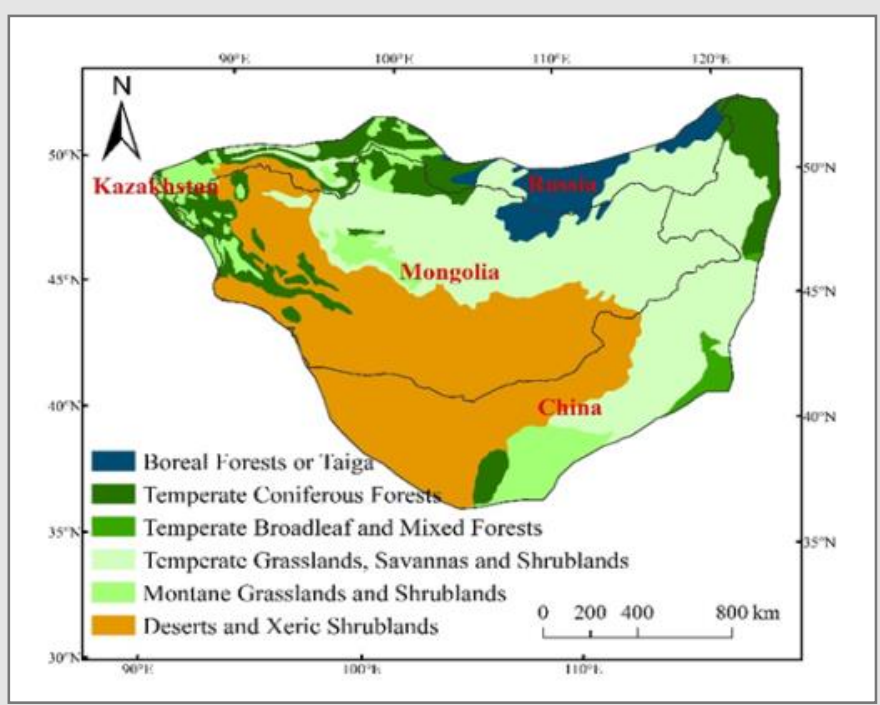

The major biomes on the Mongolian Plateau (extracted from Olson et al. 2001)

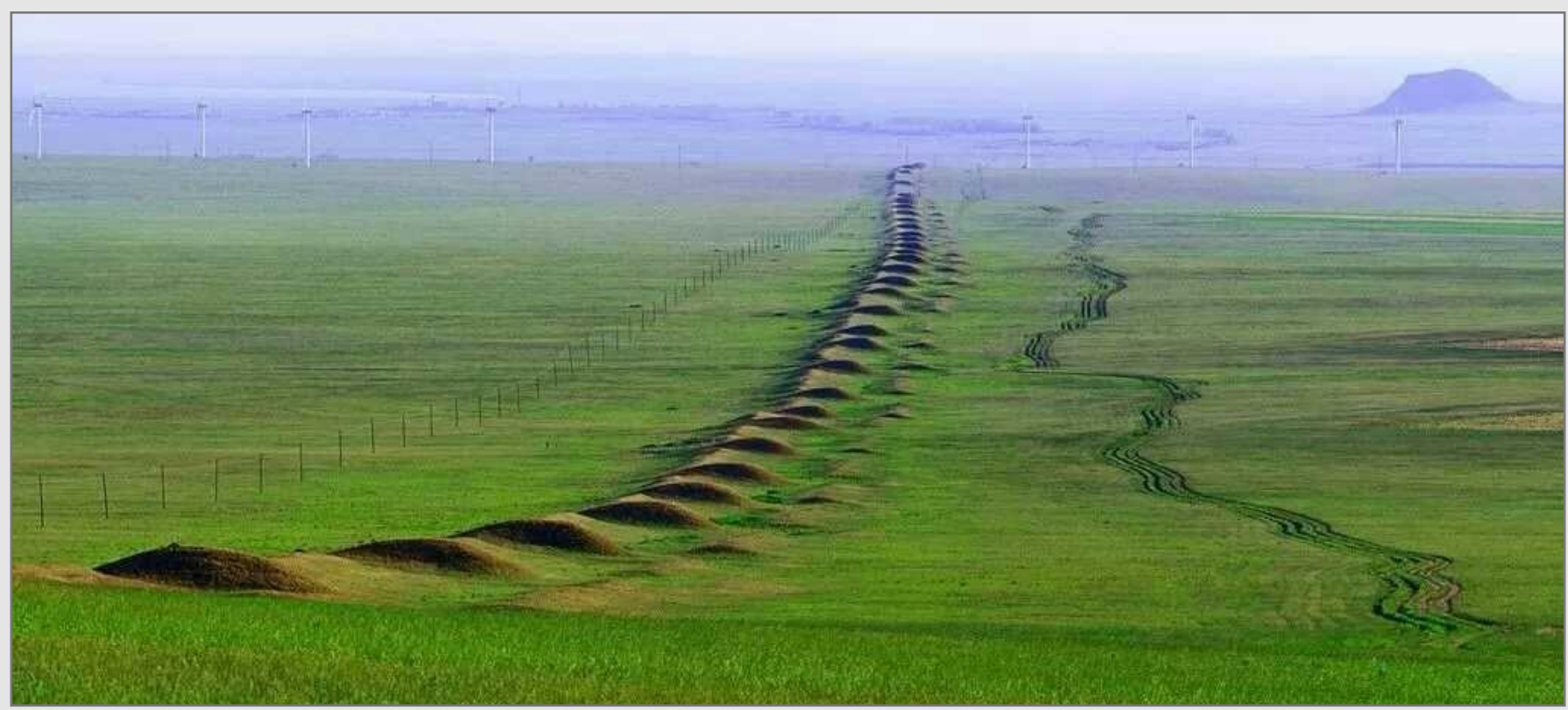

The landscape in the typical steppe region, covered by Leymus chinensis vegetation. The connected hills are the relic of the bordering wall between Nuzhen and Mongolian tribes, built in the 12th century (Jin dynasty of China). Photo: FY. Li. 

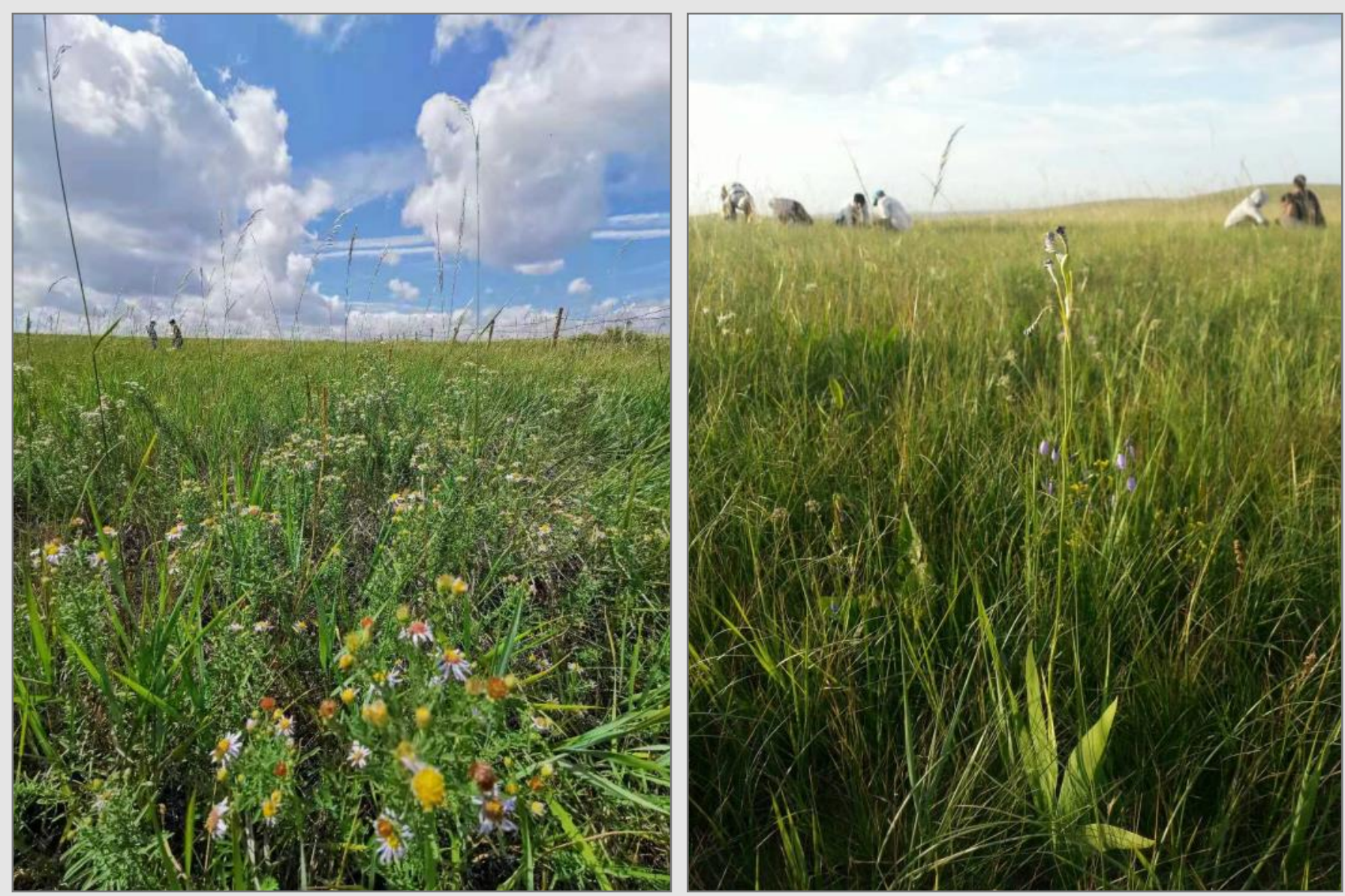

Leymus chinensis community occurs in the relatively humid habitat in the typical steppe zone. It may also form meadow steppe community with meso-xerophytes. The photos show two $L$. chinensis communities, one with a patch of flowering Heteropappus altaicus in front (left), and the other with Iris dichotoma in front, taken in central Inner Mongolia, China. Photos: FY. Li.

The climate is the driest in the central part of the Mongolian Plateau, where desert vegetation is distributed. Apart from the driest Gobi Desert area, humidity increases in all the three directions to the north, east and south in the vast area of the eastern Mongolian Plateau, and the vegetation changes successively into desert steppe, typical steppe and meadow (mountain) steppe, before finally into forest. Here we show the major grassland communities in the vast steppe region of the Mongolian Plateau along a gradient of increasing climatic aridity. More detailed information on these grasslands can be found in Li et al. (2020) and Pfeiffer et al. (2020).

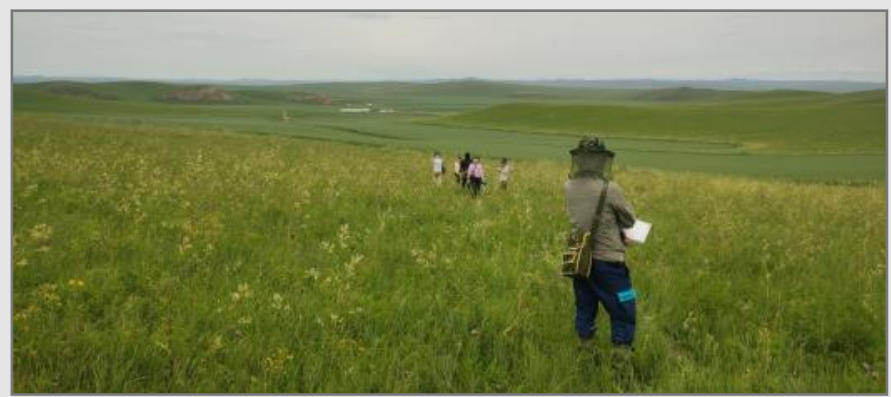

Leymus chinensis + Filifolium sibiricum meadow steppe community in the Ujumchin region (with Polygonum divaricatum). Photo: JH. Zhang.

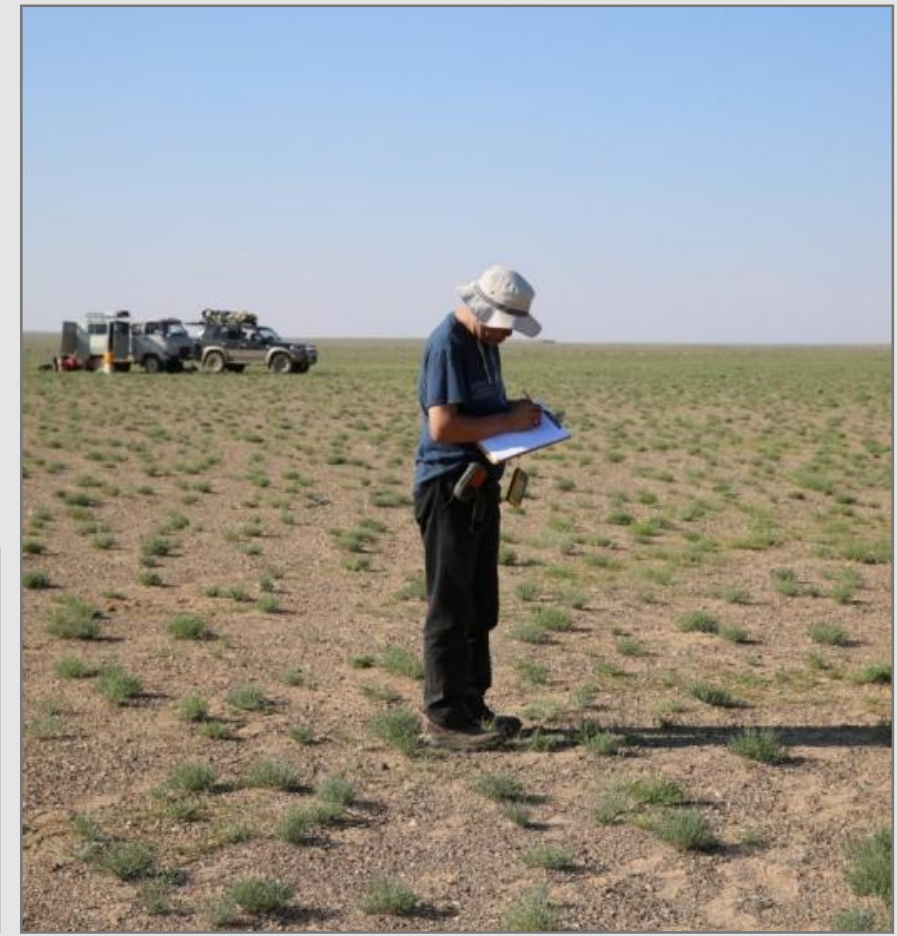

Anabasis brevifolia desert community at the border of China and Mongolia, west to Zamyn-Uud, Mongolia. Photo: TJ. Bao. 


\section{Further reading}

Li, F.Y., Jäschke, Y., Guo, K. \& Wesche, K. 2020. Grasslands of China. In: Goldstein, M.I. \& DellaSala, D.A. (eds.) Encyclopedia of the World's Biomes, vol. 3, pp. 773-784. Elsevier, Amsterdam, NL.

Pfeiffer, M., Dulamsuren, C. \& Wesche, K. 2020. Grasslands and shrublands of Mongolia. In: Goldstein, M.I. \& DellaSala, D.A. (eds.) Encyclopedia of the World's Biomes, vol. 3, pp. 759-772. Elsevier, Amsterdam, NL.

Olson, D.M., Dinerstein, E., Wikramanayake, E.D., Burgess, N.D., Powell, G.V.N., Underwood, E.C., D'amico J.A., Itoua, I., Strand, H.E., (...) \& Kassem K.R. 2001. Terrestrial ecoregions of the world: A new map of life on Earth. BioScience 51: 933-938.

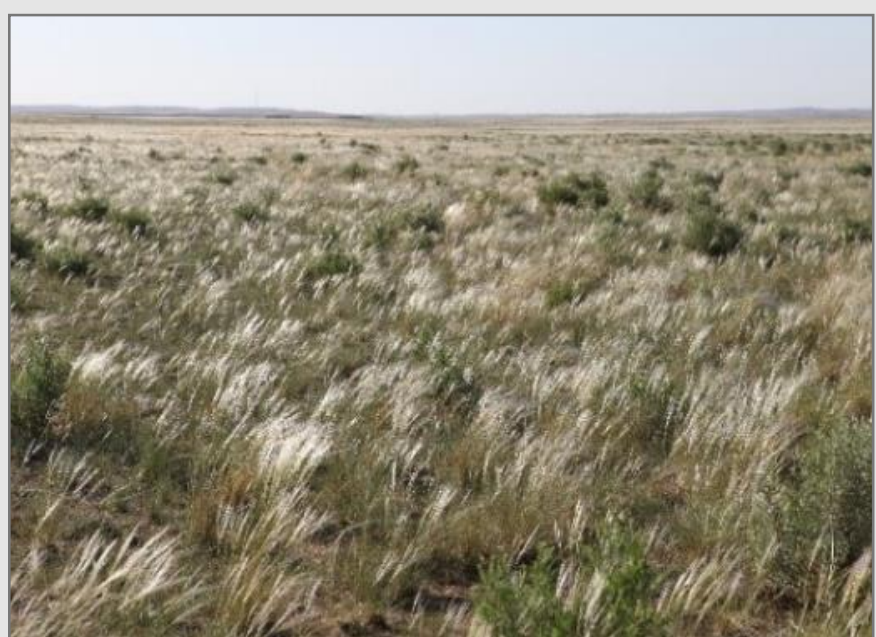

Stipa klemenzii desert steppe community in the Urad region, Inner Mongolia, China. The shrub is Caragana intermedia. Photo: LQ. Zhao.
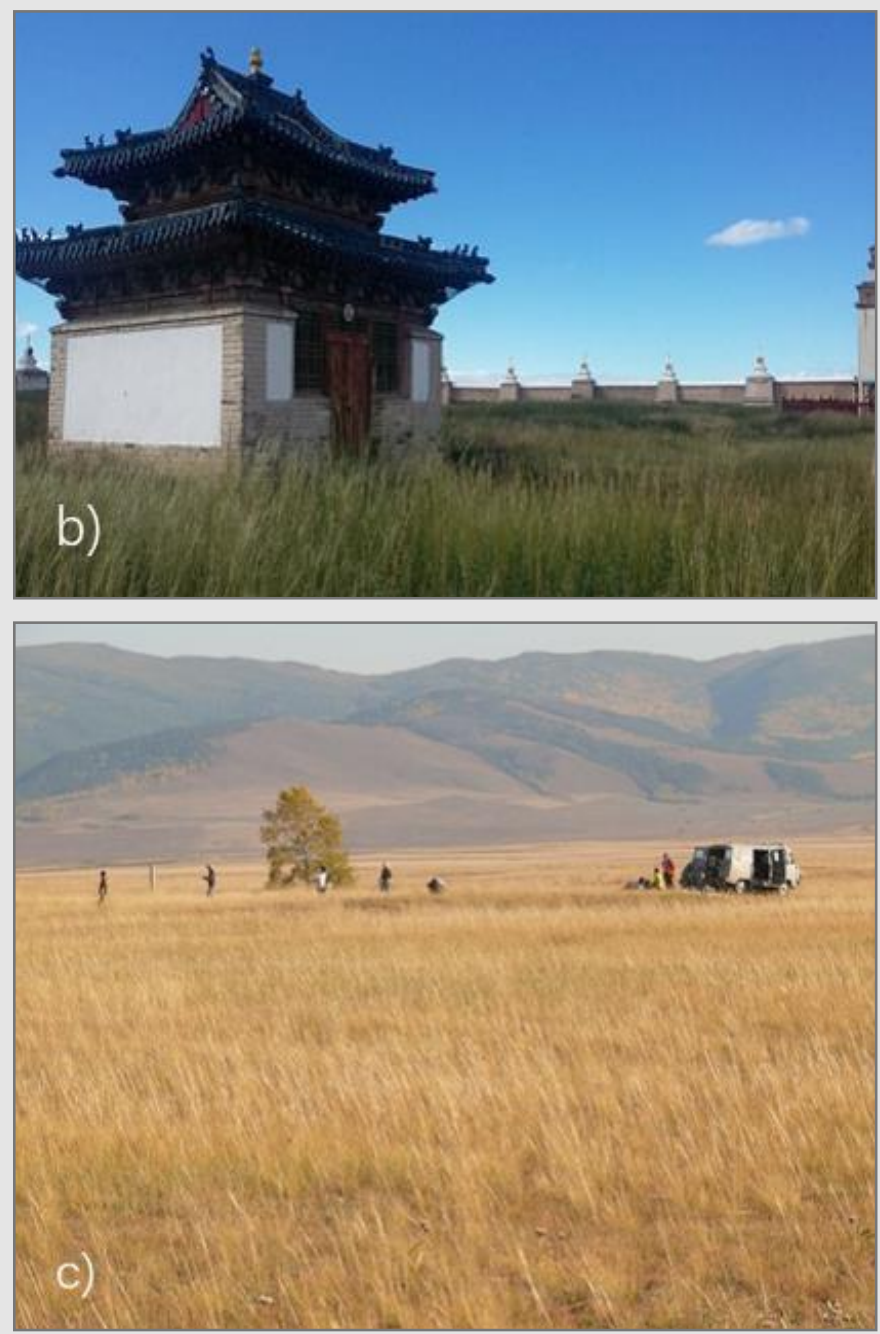

Stipa krylovii community is the most widely distributed Stipa community on the Mongolian Plateau. The photos show (a) Stipa krylovii community in the Abaga region of Inner Mongolia, China, (b) besides the Karakorum historical heritage site in central Mongolia, and (c) in the east bank area of the lake Baikal, Buryatia of Russia. Photos: FY. Li. 

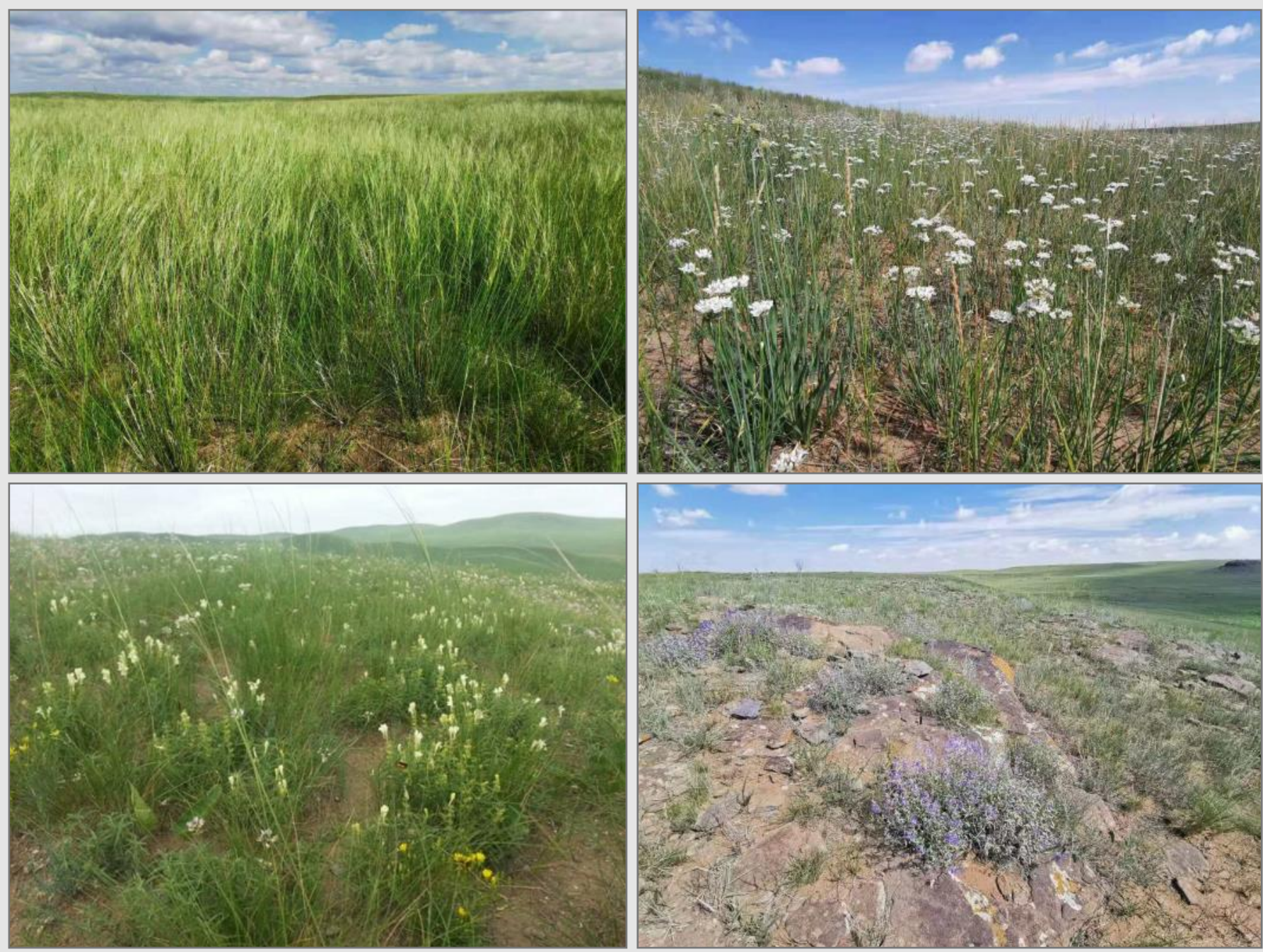

Stipa grandis community is one of the major plant communities in the zonal habitat of the typical steppe zone, although diverse plant communities may develop with the variation in landforms. The four photos show (clockwise): (a) Stipa grandis predominant community in a vast high plain, (b) Allium ramosum community (with one $A$. senescens with broad leaves on the left side) on a sandy slope, (c) Scutellaria viscidula community on a hill top, and (d) Caryopteris mongholica community on a basaltic rocky platform, all in the Xilingol region of Inner Mongolia, China. Photos: FY. Li.
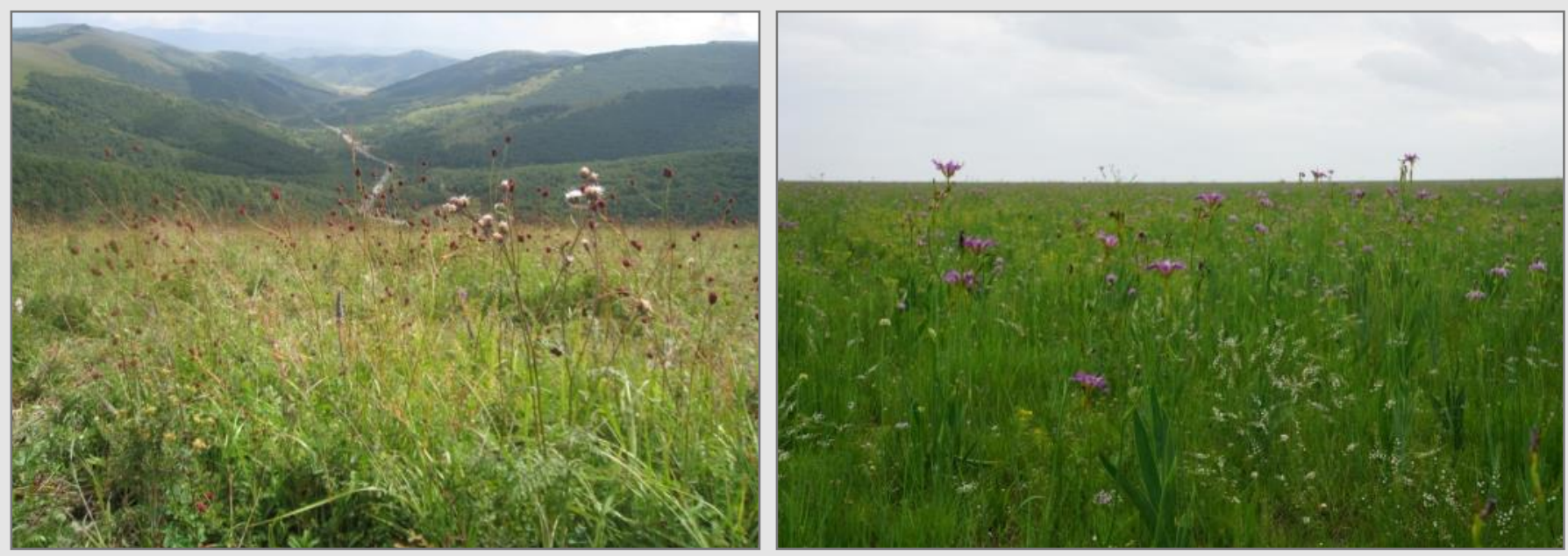

Sanguisorba officinalis meadow community in Chifeng region (left) and species-rich meadow community in Hulunbuir region (right photo), with identifiable Iris dichotoma with pink flower, Filifolium sibiricum with yellow flower and Astragalus melilotoides with white flower, in the forest-grassland ecotone region in the eastern part of the Mongolian Plateau. Photos: FY. Li and WH. Ma. 

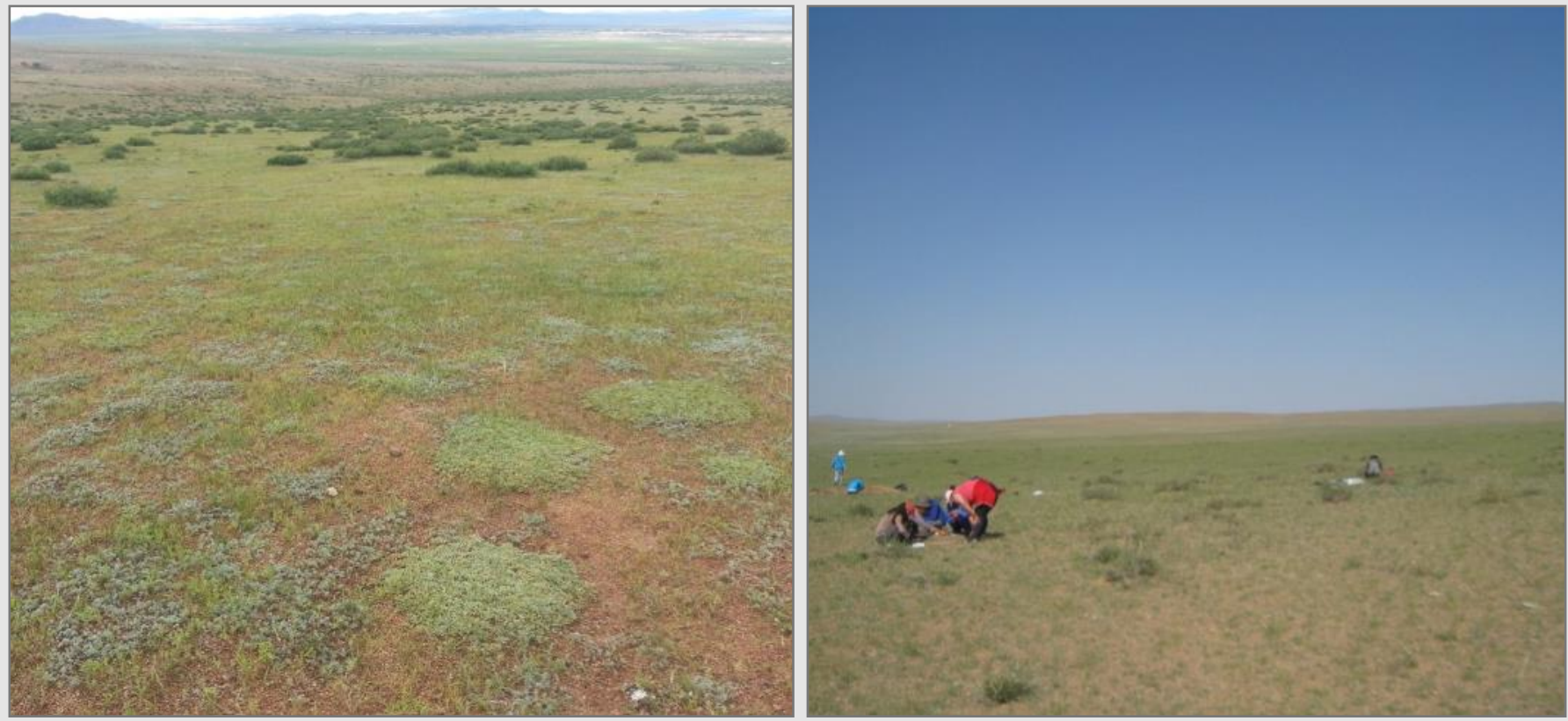

Over-grazing induced grassland degradation is common in the steppes. The Artemisia frigida + Potentilla acaulis community is typical of grassland communities degraded under long-term grazing from the primary Stipa krylovii and Leymus chinensis communities in the steppe region of the Plateau. The photos are taken in the central-north part of Mongolia. Photos: FY. Li.
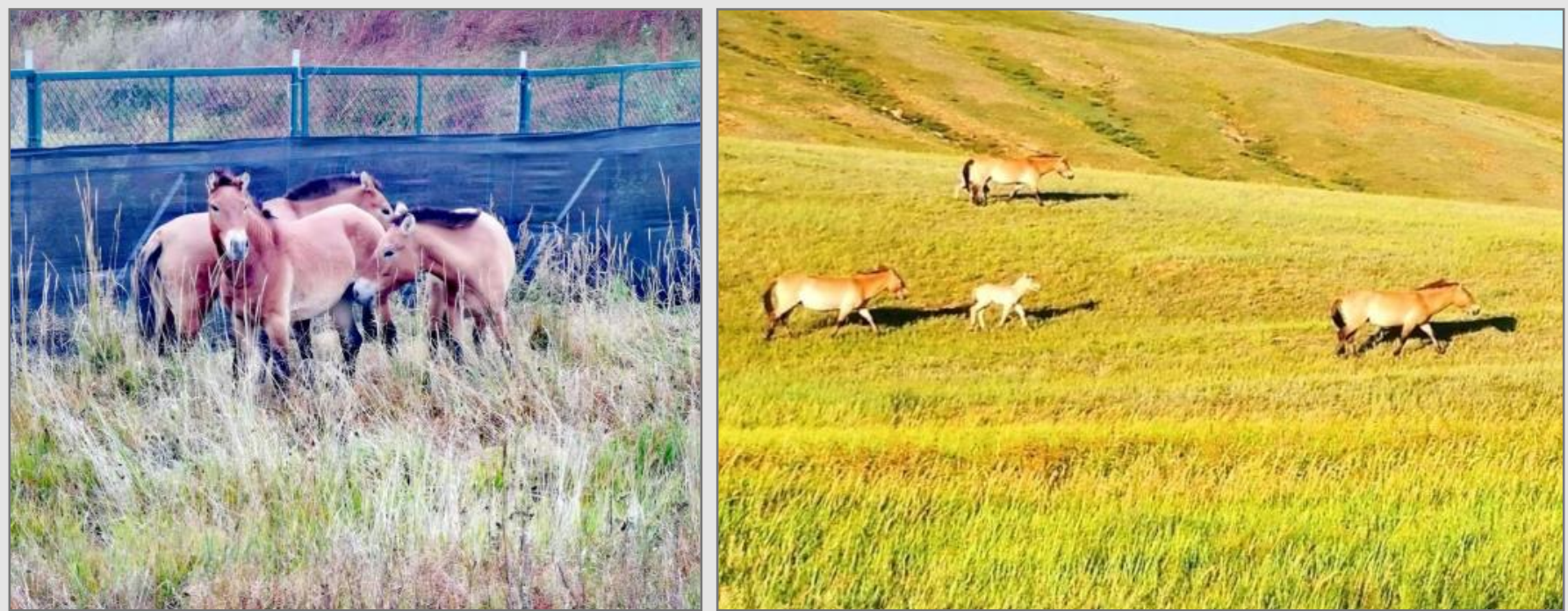

Przewalski's horse (Equus ferus subsp. przewalskii) is the keystone species of the vast steppes of the Mongolian Plateau. The horse was extinct in the fields of the Plateau in the 1940s and was re-introduced from the European zoos. The photos are taken from the Daqinshan National Nature Reserve in China (left) and the Hustai National Park of Mongolia (right). Photos: FY. Li. 


\section{Photo Competition}

\section{Best Shots on "Grassland birds"}

Here are the three winners of the EDGG Photo Competition "Grassland birds", dedicated to the bird species enlivening grassland ecosystems.

The Jury for the Photo Competition was composed of Edy Fantinato (Chair), Anna Kuzemko, Rocco Labadessa, Jim Martin, Jalil Noroozi and Salza Palpurina.

$1^{\text {st }}$ place

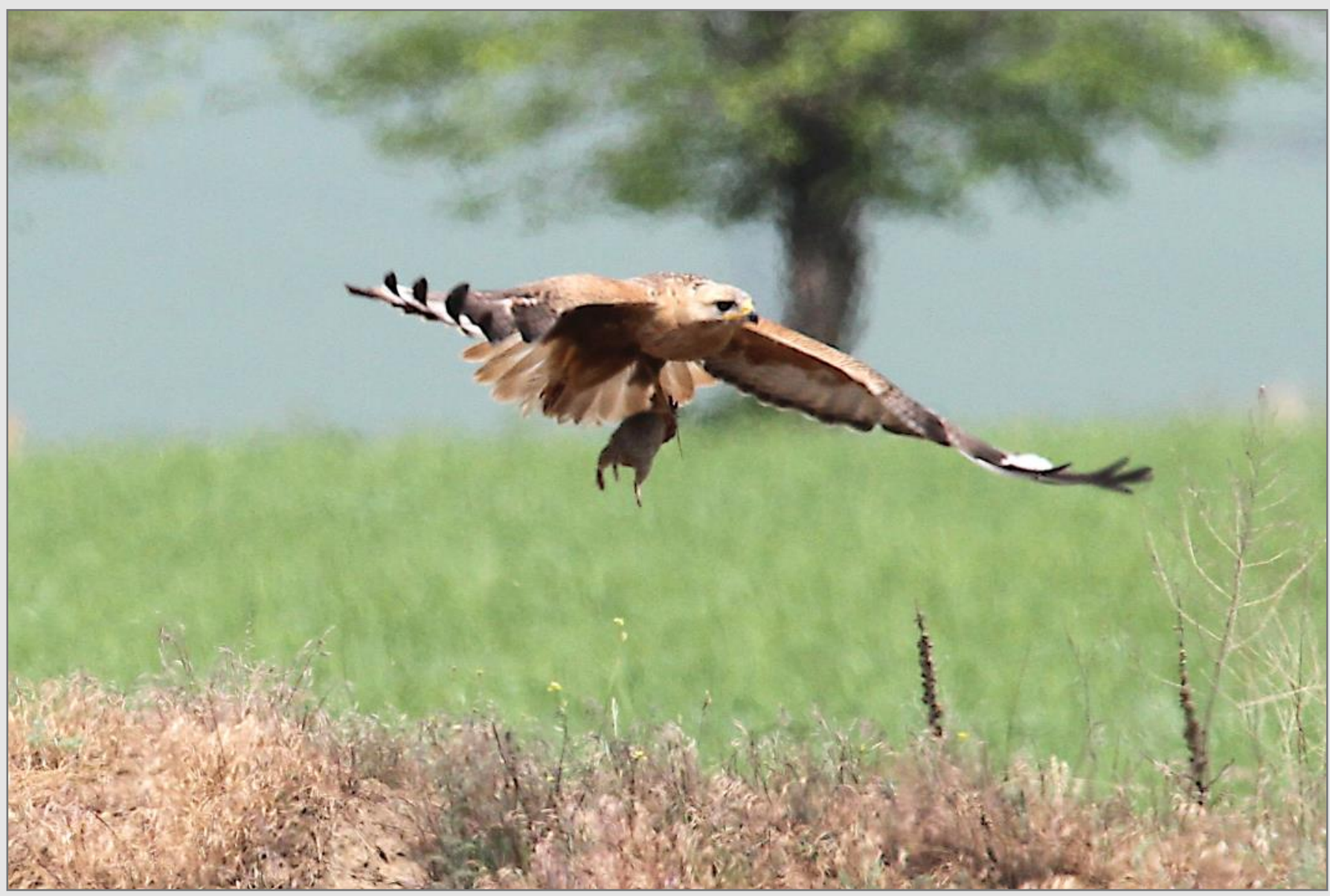

Long-legged Buzzard (with spotted suslik), Ukraine.

Paul Goriup paulgoriup@gmail.com

Reviews from the Jury:

"A stunning action shot of a raptor with prey in talons sweeping across the grassland."

"Despite the imperfect technical value, the shot is able to depict an impressive hunting scene."

"Kudos to the photographer for this amazing shot of the raptor with its prey. I like it also because grasslands - as the main focus of the Journal and topic - are visible in the foreground." 


\section{$2^{\text {nd }}$ place:}

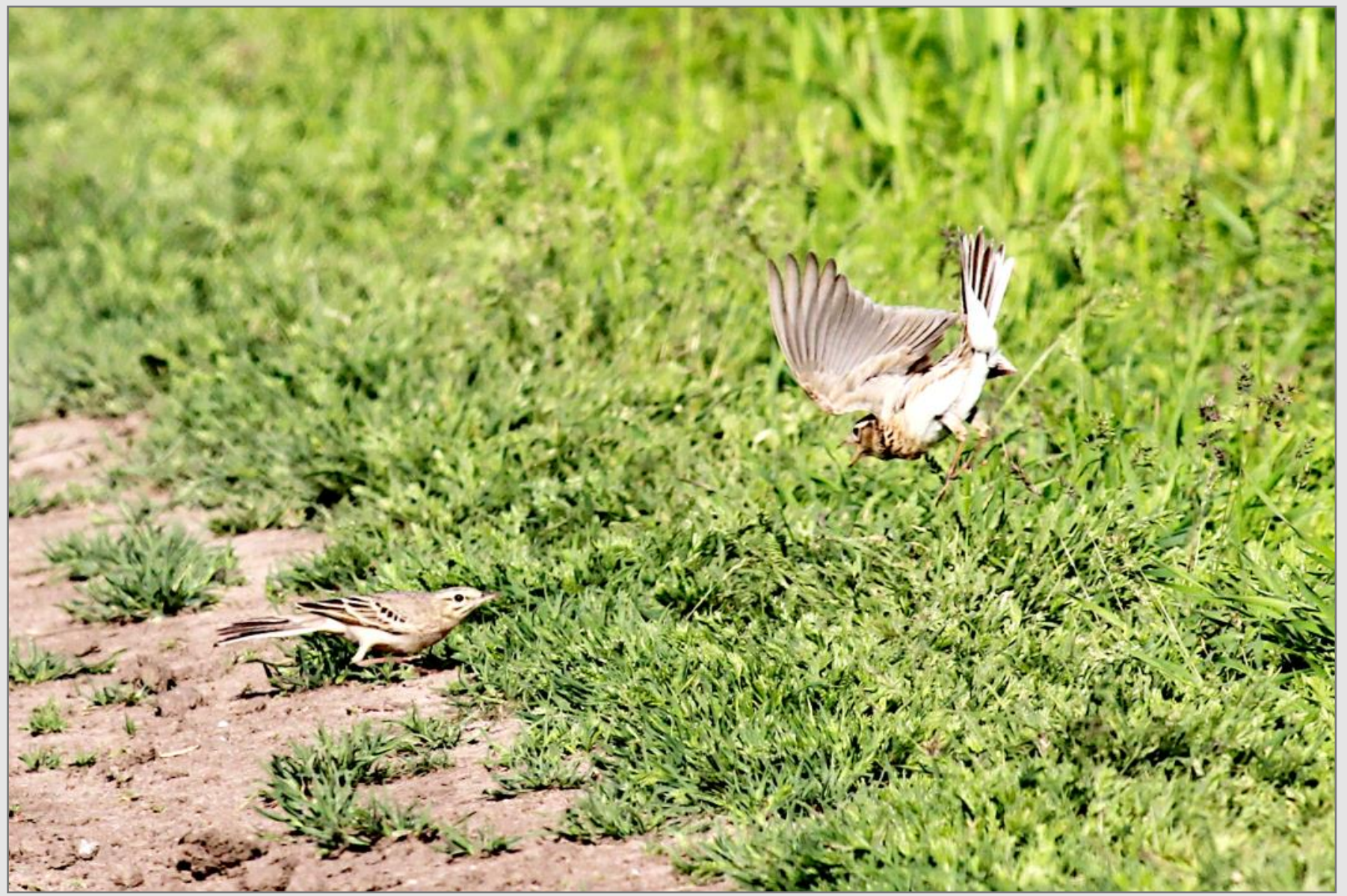

Skylark attacking Tawny Pipit, Ukraine.

Paul Goriup

paulgoriup@gmail.com

Reviews from the Jury:

"A great photo of two birds squabbling over territory." 
$3^{3 d}$ place:

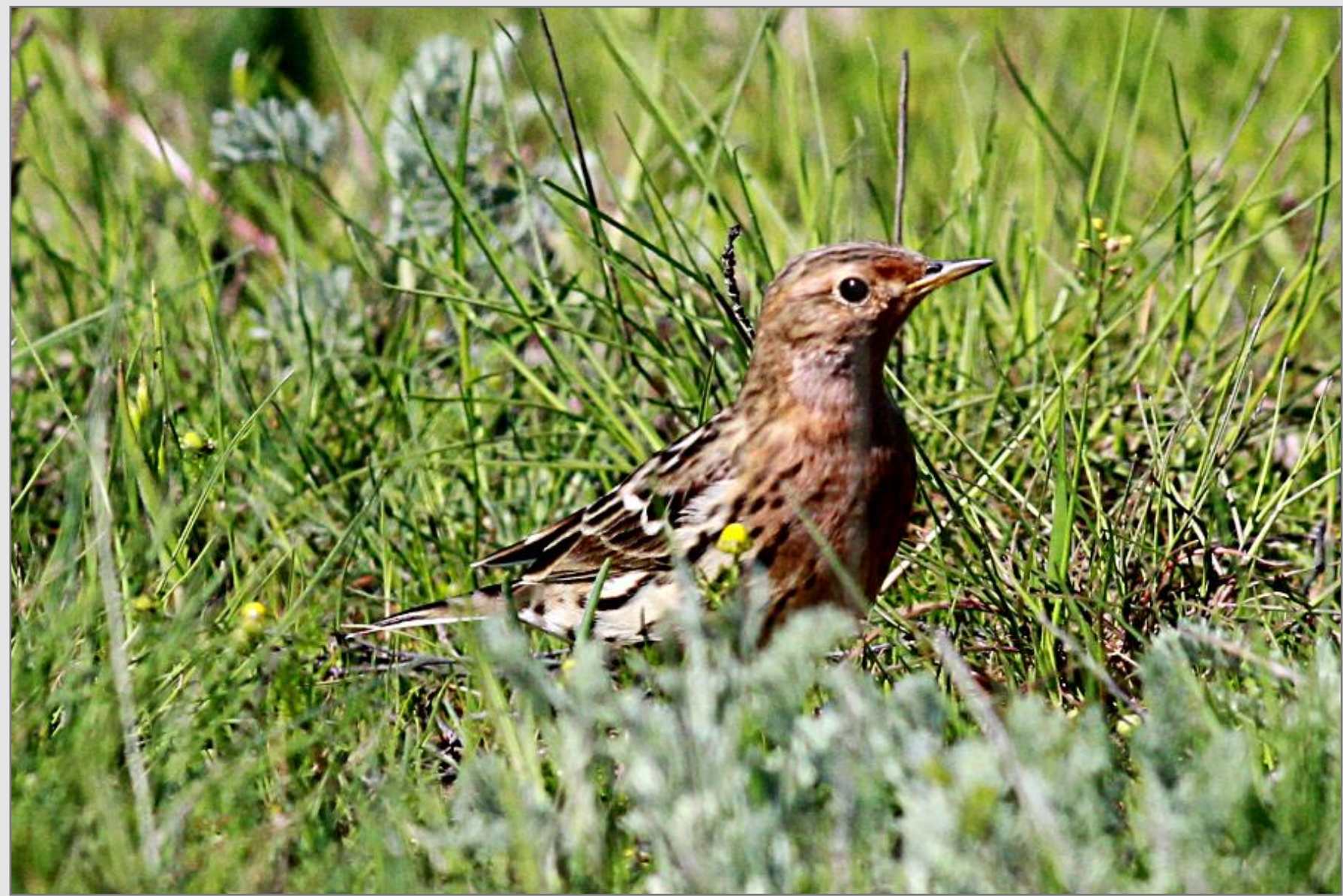

Red-throated Pipit, Ukraine.

Paul Goriup

paulgoriup@gmail.com

Reviews from the Jury:

"Nice composition showing the passerine bird amongst the grassland."

General comments on the three selected shots:

"I preferred the photos showing birds in their grassland habitat. Birds are generally difficult to photograph and even more difficult to capture the moments of their life, especially the hunt as in the photo that received first place, or their restless relationship as in the photo that received second place. These photos are very dynamic and that is exactly why they are so attractive." 


\section{Short Contributions}

\section{A decision-making tool for restoring lowland grasslands in Europe}

In lowland Europe, the vast majority of species-rich grasslands are in an unfavourable conservation status (European Commission, 2020), which requires urgent restoration measures. A significant amount of information on the results of previous restorations exists thanks to the implementation of numerous projects and the publication of action plans, technical notes and scientific articles. This information is however very scattered, which does not facilitate decision making. In Belgium, a partnership between practitioners and scientists tried to fill this gap during grassland restoration projects. The partnership consisted of the NGO Natagora, the Department of Nature and Forests and the Department of Natural and Agricultural Environment of the Wallonia Public Service, and Meise Botanic Garden.

In a recent publication (Goret et al. 2021), they propose a decision support tool using a step-wise framework informed by a review of scientific and grey literature, supplemented by lessons learnt during two large-scale restoration projects implemented on 850 ha spread over more than 100 different sites. After 8 years of implementation of restoration techniques, they had enough hindsight (Figs. 1, 2, 3) to propose a easy to use framework for practitioners to assist them with decisions in specific situations. The decision tree starts with an analysis of the situation before restoration, which includes aspects to be considered in general in any habitat restoration, such as philosophical acceptance, preliminary assessment, project aim, its feasibility, risks and sustainability. Different restoration techniques are then applied based on the soil nutrient status, the intensity of habitat degradation, the presence of nearby habitat in good conservation status, and ongoing management to apply after restoration depending on the type of grassland.
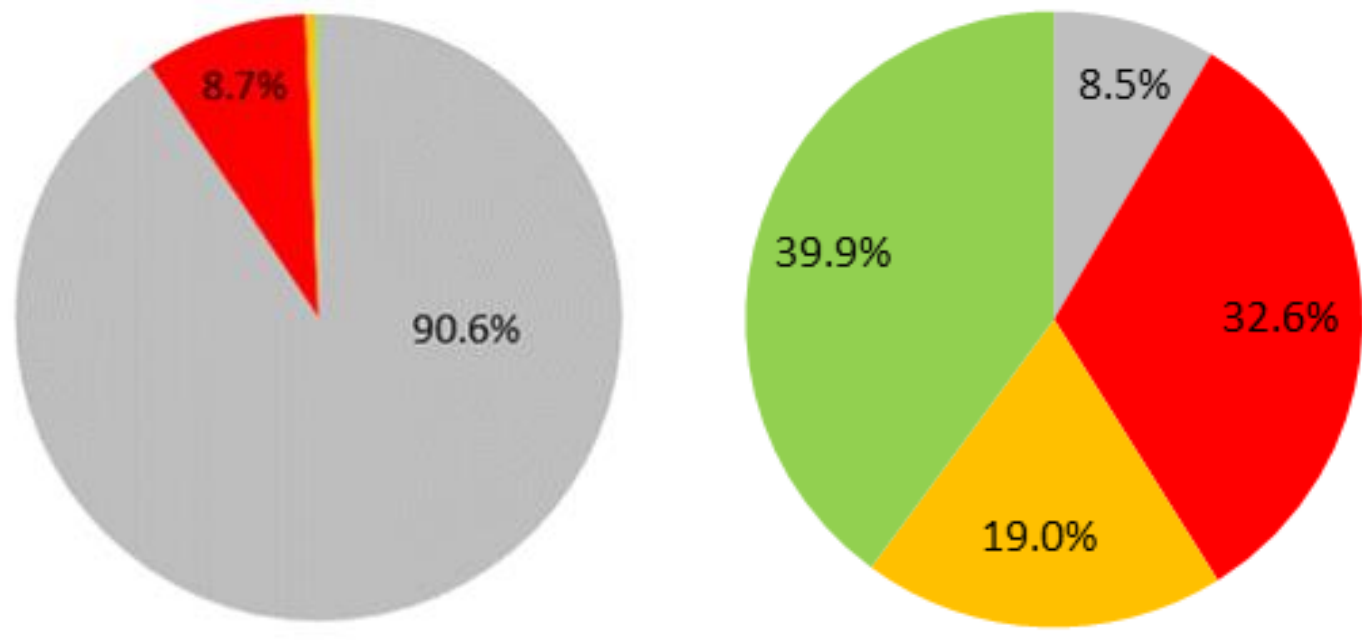

None

- Bad

Average

Good

Fig. 1. Change in grassland quality under the "LIFE Herbages" project (LIFE11NAT/BE/001060) that took place between 2013 and 2020. Left: grassland quality before restoration. Average number of typical species $=0.5$ (1.4\% cover). Right: grasslands quality after restoration. Average number of typical species $=5.4(24.1 \%$ cover). $n=179$ plots (totalling 273 ha). 
This synthesis is presented as a step by step dichotomous key which is intended to assist practitioners in making their restoration work a success. This contribution is timely in the context of the UN Decade on Ecosystem Restoration (20212030) and the continuous and widespread degradation of these habitats across much of Europe.

\section{References}

European Commission. 2020. The State of Nature in the EU - Conservation status and trends of species and habitats protected by the EU Nature Directives 2013-2018. Retrieved from https://ec.europa.eu/environment/nature/knowledge/ rep habitats/index en.htm [accessed 22 February 2021].
Goret, T., Janssens, X. \& Godefroid, S. 2021. A decision-making tool for restoring lowland grasslands in Europe. Journal for Nature Conservation 63: e126046. DOI: 10.1016/j.jnc.2021.126046

Sandrine Godefroid, Belgium sandrine.godefroid@botanicgardenmeise.be

Thibaut Goret, Belgium thibaut.goret@natagora.be

Xavier Janssens, Belgium xavier.janssens@natagora.be
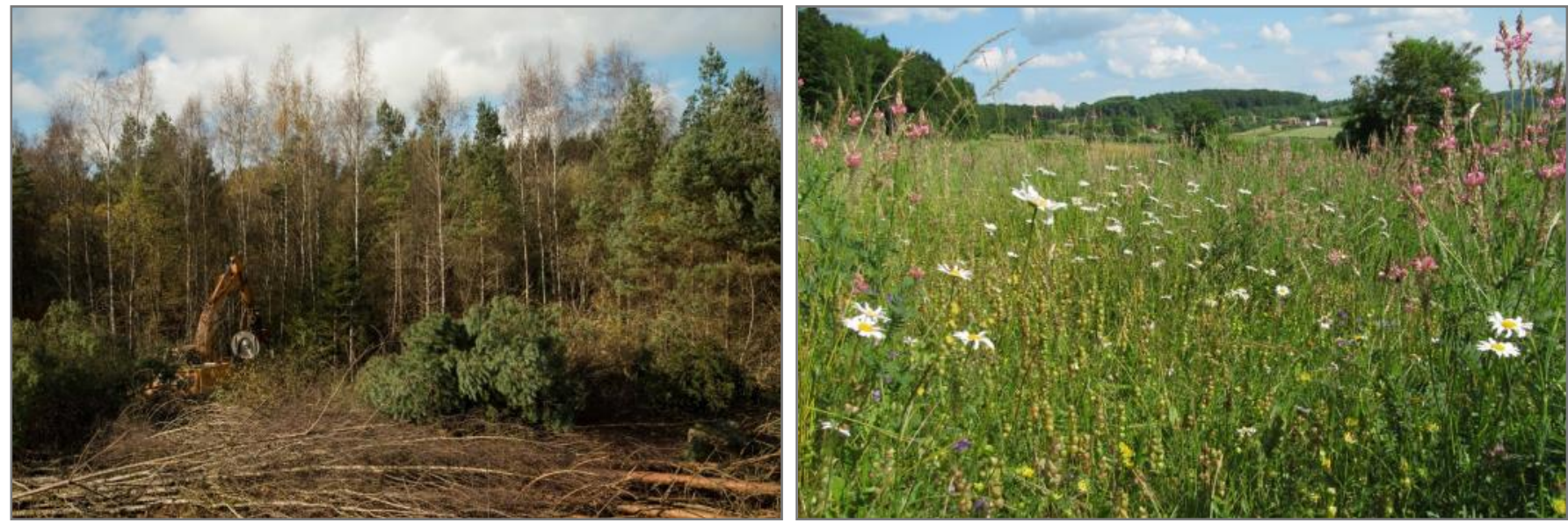

Fig. 2. Left: situation before restoration: plantation of exotic conifers. Right: restored dry grasslands on calcareous substrate (habitat 6210) using a mixture of seeds harvested from grasslands in good conservation status in the same phytogeographic region, supplemented by plug planting after ex situ propagation of rare species. Photos: left, $\mathrm{X}$. Janssens; right, S. Godefroid.
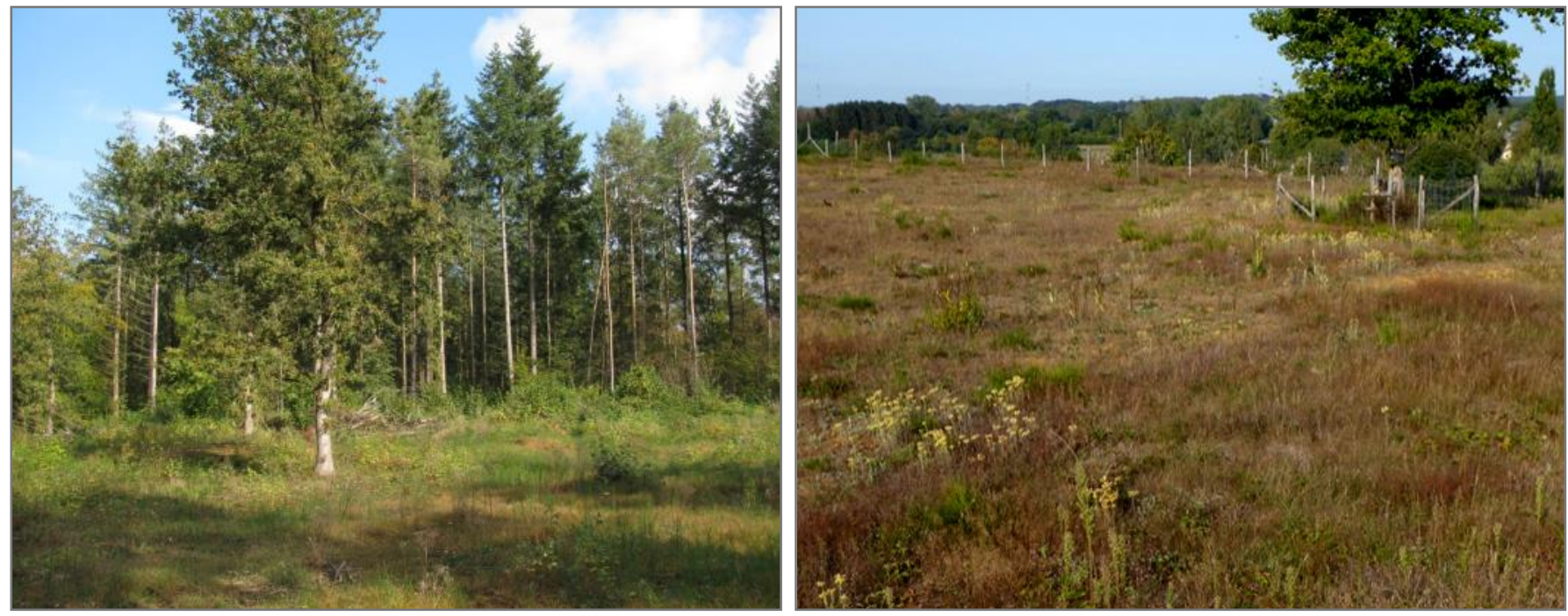

Fig. 3. Left: situation before restoration: plantation of exotic conifers. Right: restored xeric sand calcareous grasslands (habitat 6120) using a mixture of seeds harvested from grasslands in good conservation status in the same phytogeographic region, supplemented by plug planting after ex situ propagation of rare species. Photos: S. Godefroid. 


\section{Call for a Special Issue in Biologia Biological Invasions in the $21^{\text {st }}$ century: a global risk}

Biological invasions refer to the introduction, establishment and expansion of alien species from other geographical areas. Most of these invasions have been caused by accidental introductions, but in other cases have been intentional. This transfer of species has been carried out for a long time but without doubt human movements, intensification of trade, ecosystems alteration and further development have accelerated the process. Therefore, biological invasions are globally recognized as a primary cause of biodiversity loss and can profoundly alter ecosystem properties and native biodiversity.

The aim of this Special Issue is to bring together a set of reviews and research articles about all aspects of plant invasion biology, with an emphasis on patterns and processes of biological invasions in terrestrial, freshwater and marine ecosystems. Scholarly papers on management and policy issues as they relate to conservation programs and the global control of invasions are also of interest. This Special Issue also welcomes risk management frameworks including strategies for the management of species or their impacts.

The objective of this Special Issue is to deepen the knowledge of biological invasions (e.g. routes of introduction of invasive species, most invaded regions and habitats, characteristics of invasive species, genetic diversity of inva- sive versus native species, modification of ecosystems, species control management, etc.). Furthermore, specific case studies are welcome.

We think you could make an excellent contribution based on your academic expertise and publication record. For further information, please follow the link to the Special Issue Website at: https://www.springer.com/journal/11756.

We encourage authors to send a short abstract or tentative title to the Editors in advance (katarina.hegedusova@savba.sk, cireseduardo@gmail.com).

The submission deadline for abstracts is 15 December 2021, and submission deadline for articles (Biologia) is $\mathbf{3 0}$ April 2022. Submitted papers should not be under consideration for publication elsewhere.

For further details on the submission process, please see the instructions for authors at the journal website.

We look forward to hearing from you soon.

Editors

Katarína Hegedüšová, Slovakia katarina.hegedusova@savba.sk

Eduardo Cires, Portugal cireseduardo@gmail.com
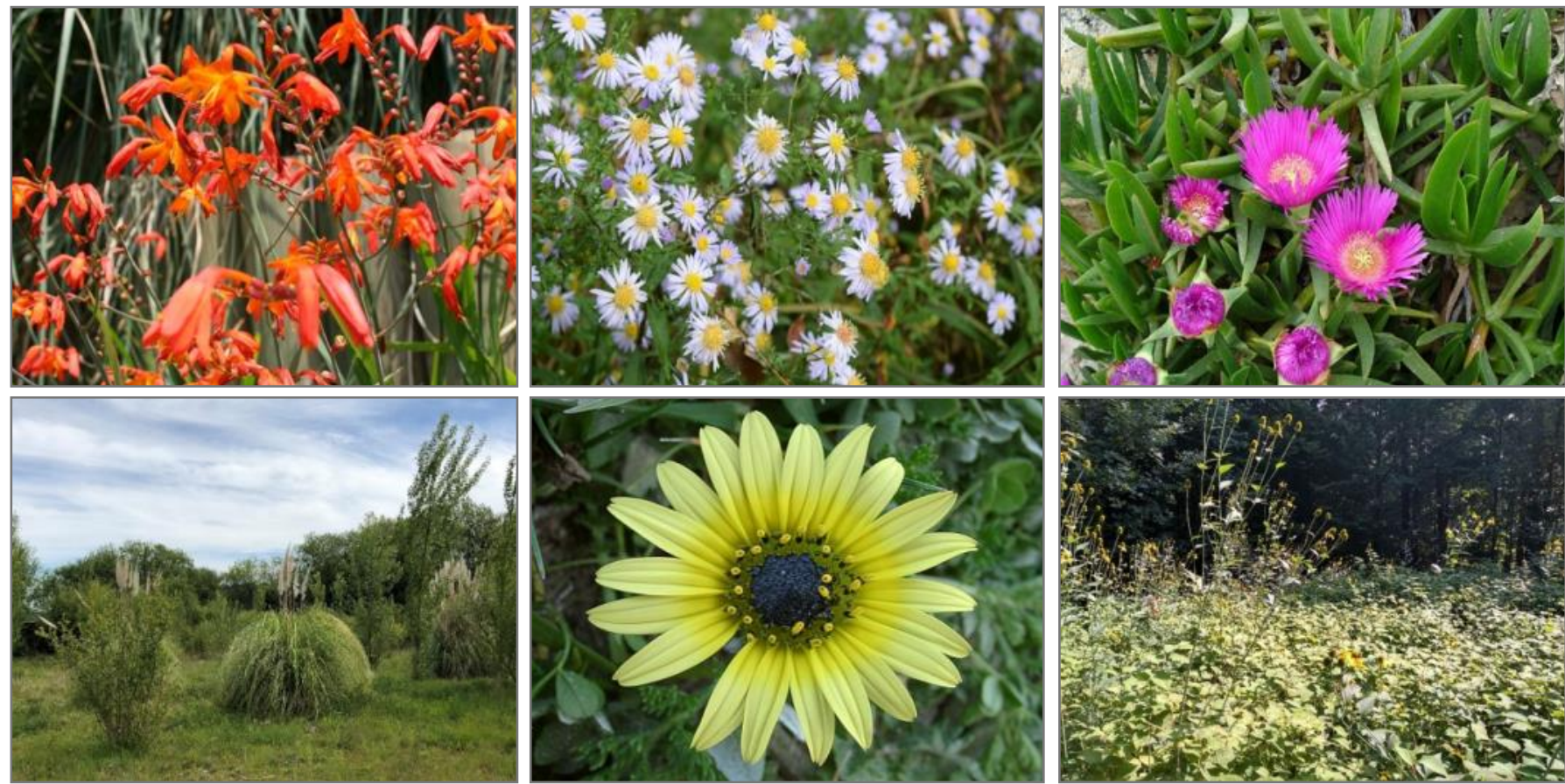

Crocosmia x crocosmiiflora, Symphyotrichum lanceolatum, Carpobrotus acinaciformis, Cortaderia selloana, Arctotheca calendula, Rudbeckia laciniata and Reynoutria japonica. Photos: E. Cires and K. Heg edüšová. 


\section{Recent Publications of our Members}

In this section, the contents of which will also be made available via our homepage, we want to facilitate an overview of grassland-related publications throughout Eurasia and to improve their accessibility. You are invited to send lists of such papers from the last three years following the format below to Iwona Dembicz, i.dembicz@gmail.com. We will include your e-mail address so that readers can request a pdf. For authors who own full copyright, we can also post a pdf on the EDGG homepage.

\section{Biodiversity \& ecology}

Boch, S., Becker, T., Deák, B., Dengler, J. \& Klaus, V.H. 2021. Grasslands of temperate Europe in a changing world - Editorial to the 16th EDGG Special Feature in Tuexenia. Tuexenia 41: 351-359. doi: $10.14471 / 2021.41 .020$

Boch, S., Kurtogullari, Y., Allan, E., Lessard-Therrien, M., Rieder, N.S., Fischer, M., Martínez De León G., Arlettaz, R. \& Humbert, J.-Y. 2021. Effects of fertilization and irrigation on vascular plant species richness, functional composition and yield in mountain grasslands. Journal of Environmental Management 279: e111629. doi: 10.1016/j.jenvman.2020.111629

Charmillot, K., Hedinger, C., Babbi, M., Widmer, S. \& Dengler, J. 2021. Vegetation change in meso-xeric grasslands of the Swiss Jura Mts. over 40 years. Tuexenia 41: 441-457. doi: $\underline{10.14471 / 2021.41 .019}$

Deák, B., Báthori, F., Lőrinczi, G., Végvári, Z., Nagy, D., Mizser, S., Torma, A., Valkó, O. \& Tóthmérész, B. 2021. Functional composition of ant assemblages in habitat islands is driven by local factors and landscape composition. Scientific Reports 11: e20962. doi: 10.1038/s41598-021-00385-5

Kummli, J., Widmer, S., Wilhelm, M., Dengler, J. \& Billeter, R. 2021. Vegetation changes in urban grasslands over 25 years in the city of Zurich, Switzerland. Tuexenia 41: 423-440. doi: $\underline{10.14471 / 2021.41 .018}$

Le Provost, G., Thiele, J., Westphal, C., Penone, C., Allan, E., Neyret, M., van der Plas, F., Ayasse, M., Bardgett, R.D., Birkhofer, K., Boch, S., (...) \& Manning, P. 2021. Contrasting responses of above- and belowground diversity to multiple components of land-use intensity. Nature Communications 12: e3918. doi: 10.1038/s41467-021-23931-1

Magnes, M., Willner, W., Janišová, M., Mayrhofer, H., Afif Khouri, E., Berg, C., Kuzemko, A., Kirschner, P., Guarino, R, Rötzer, H., Belonovskaya, H., Berastegi, A., Biurrun, I., García-Mijangos, I., Masic, E., Dengler, J. \& Dembicz, I. 2021. Xeric grasslands of the inner-alpine dry valleys of Austria - new insights into syntaxonomy, diversity and ecology. Vegetation Classification and Survey 2: 133-157. doi: $10.3897 / V C S / 2021 / 68594$

Oelmann, Y., Lange, M., Leimer, S., Roscher, C., Aburto, F., Alt, F., Bange, N., Berner, D., Boch, S., Boeddinghaus, (...) \& Wilcke, W. 2021. Above- and belowground biodiversity jointly tighten the $\mathrm{P}$ cycle in agricultural grasslands. Nature Communications 12: e4431. doi: 10.1038/s41467-021-24714-4

\section{Conservation \& restoration}

Kiss, R., Deák, B., Tóthmérész, B., Miglécz, T., Tóth, K., Török, P., Lukács, K., Godó, L., Körmöczi, Z., Radócz, S., Borza, S., Kelemen, A., Sonkoly, J., Kirmer, A., Tischew, S. \& Valkó, 0. 2021. Zoochory on and off: A field experiment for traitbased analysis of establishment success of grassland species. Journal of Vegetation Science 32: e13051. doi: 10.1111/JVS.13051
Lukács, K. \& Valkó, O. 2021. Human-vectored seed dispersal as a threat to protected areas: Prevention, mitigation and policy. Global Ecology and Conservation 31: e01851. doi: 10.1016/j.gecco.2021.e01851

\section{Methodology, classification, databases}

Sabatini, F.M., Lenoir, J., Hattab, T., Arnst, E.A., Chytrý, M., Dengler, J., De Ruffray, P., Hennekens, S.M, Jandt, U., Jansen, F., (...) \& Bruelheide, H. 2021. sPlotOpen - An environmentally balanced, open-access, global dataset of vegetation plots. Global Ecology and Biogeography 30: 1740-1764. doi: 10.1111/geb.13346

\section{Contact persons:}

Steffen Boch: steffen.boch@wsl.ch Balázs Deák: debalazs@gmail.com Jürgen Dengler: dr.juergen.dengler@gmail.com Orsolya Valkó: valkoorsi@gmail.com

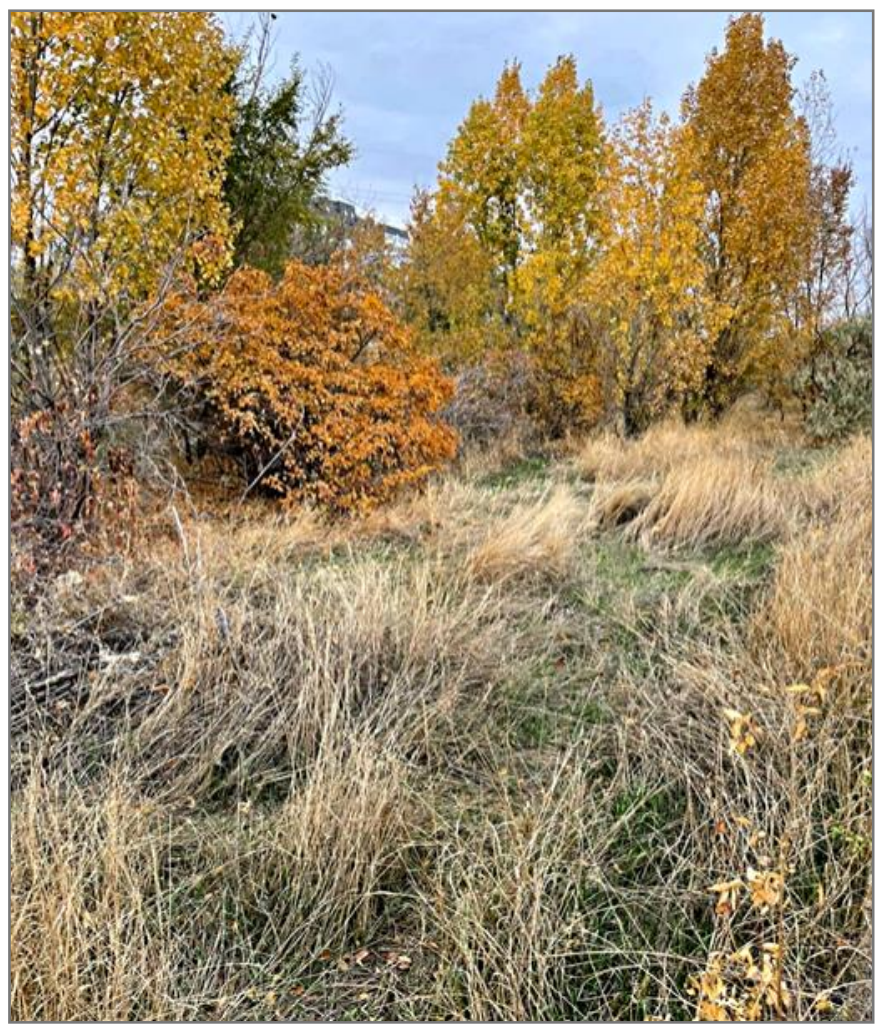

Autumn grassland near the forest protective stripe near "All-Union Scientific Research Institute of Agroforestry", Volgograd region, Russia. Photo: K. Trubakova. 


\section{Forthcoming Events}

\section{Ecology Across Borders 2021}

12-15 December 2021, Liverpool, UK

Conference website: https://www.britishecologicalsociety.org/ events/bes-annual-meeting-2020/ecology-across-borders-2021/

\section{$30^{\text {th }}$ International Congress for Conservation Biology} (ICCB) 2021

12-16 December 2021, Kigali, Rwanda

Conference website: https://conbio.org/mini-sites/iccb-2021

Asian Grassland Conference (AGC) of the EDGG

22-24 February 2022, Virtual event

See details in Palearctic Grasslands 50, pp. 9-16.
EDGG Field Workshop "Latitudinal transect in Ukraine" May 2022, Ukraine

\section{0th EVS Workshop}

9-13 May 2022, Bratislava, Slovakia

\section{4th Annual Symposium of IAVS 2022}

27 June - 1 July 2022, Madrid, Spain

Symposium website: https://iavsmadrid2022.com

Eurasian Grassland Conference (EGC) of the EDGG

5-11 September 2022, Tolosa, Spain

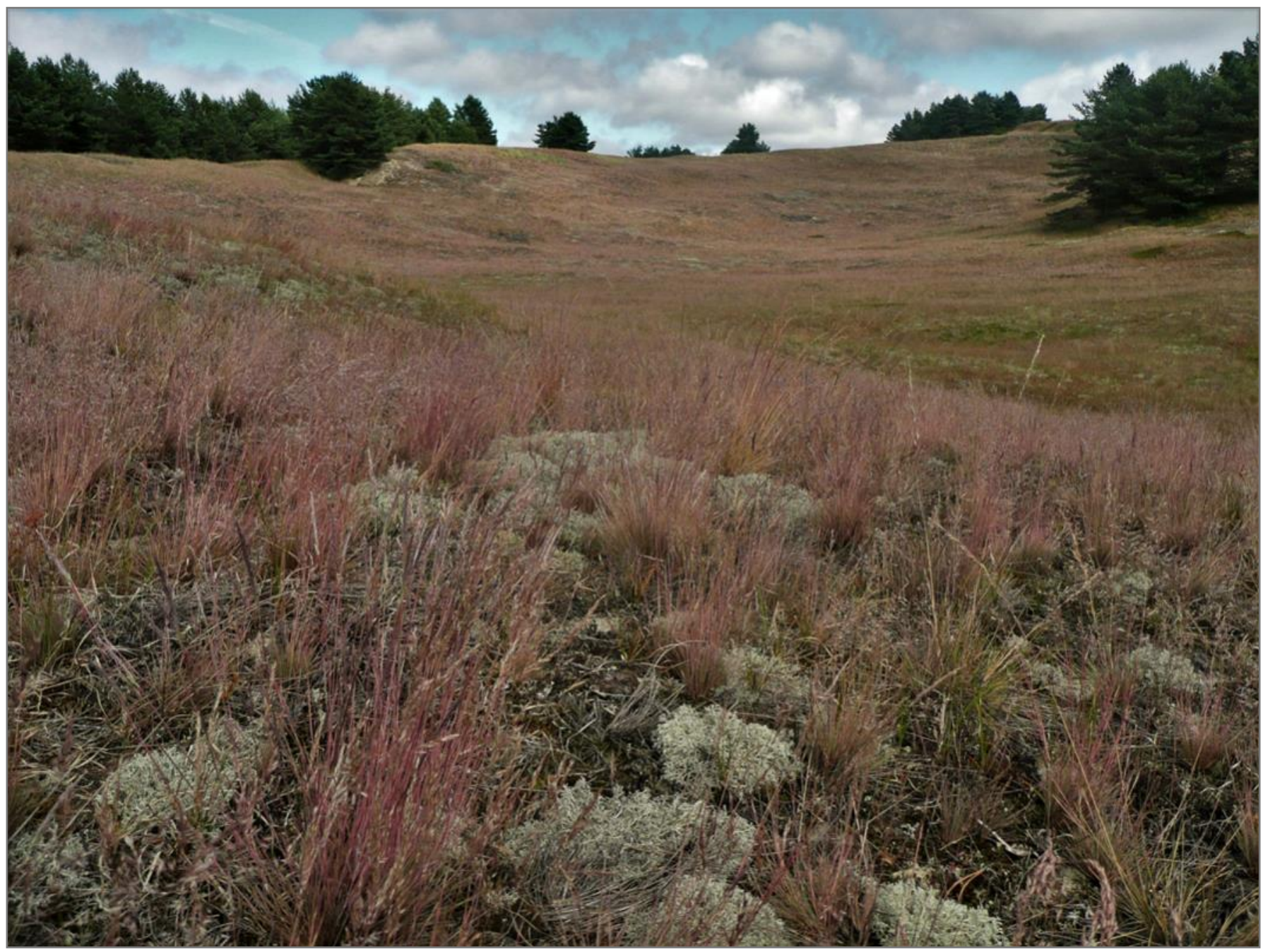

Sandy grassland on the Curonian Spit, Lithuania. Photo J. Sonkoly. 


\section{eDGG}

Grass[and] research and conservation
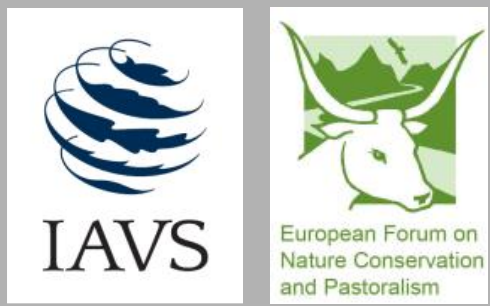

EDGG on the web:

http://www.edgg.org

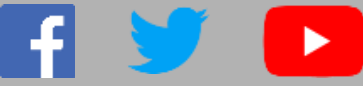

The Eurasian Dry Grassland Group (EDGG), founded in 2008, is a working group of the International Association for Vegetation Science (IAVS) and member of the European Forum on Nature Conservation and Pastoralism (EFNCP). On 25 August 2021, it had 1352 members from 64 countries.

The Eurasian Dry Grassland Group (EDGG) is a network of researchers and conservationists interested in any type of Palaearctic natural and semi-natural grasslands. It is an official Working Group of IAVS (http://www.iavs.org) but one can join our group without being an IAVS member. We live from the activities of our members. Everybody can join the EDGG without any fee or other obligation.

The EDGG covers all aspects related to grasslands, in particular: plants - animals - fungi - microbia - soils - taxonomy - phylogeography - ecophysiology - population biology - species' interactions - vegetation ecology - syntaxonomy - landscape ecology - biodiversity - land use history - agriculture - nature conservation - restoration - environmental legislation - environmental education.

\section{EDGG Executive Committee and responsibilities of its members}

Alla Aleksanyan, Armenia, alla.alexanyan@gmail.com Editor of Website; Deputy Conference Coordinator; member of the Editorial Board of Palaearctic Grasslands

Didem Ambarlı, Turkey, didem.ambarli@gmail.com Conference Coordinator, Deputy Secretary-General; Deputy Coordinator for Special Features, member of the Editorial Board of Palaearctic Grasslands

Idoia Biurrun, Spain, idoia.biurrun@ehu.es

Membership Administrator; Deputy Treasurer and Representative to IAVS; Chief Editor of Palaearctic Grasslands; Deputy Field Workshop Coordinator

Iwona Dembicz, Poland, i.dembicz@gmail.com Field Workshop Coordinator; member of the Editorial Board of Palaearctic Grasslands
Jürgen Dengler, Switzerland, dr.juergen.dengler@gmail.com Secretary-General; Treasurer and Representative to IAVS; Special Feature Coordinator; Chief Editor of Palaearctic Grasslands

Anna Kuzemko, Ukraine, anyameadow.ak@gmail.com Chief Editor of Palaearctic Grasslands; Deputy Social Media Administrator

Rocco Labadessa, Italy, rocco.labadessa@gmail.com

Chief Editor of Palaearctic Grasslands; Deputy Editor of Website

Stephen Venn, Finland, stephen.venn@helsinki.fi Social Media Administrator; Deputy Conference Coordinator; member of the Editorial Board of Palaearctic Grasslands

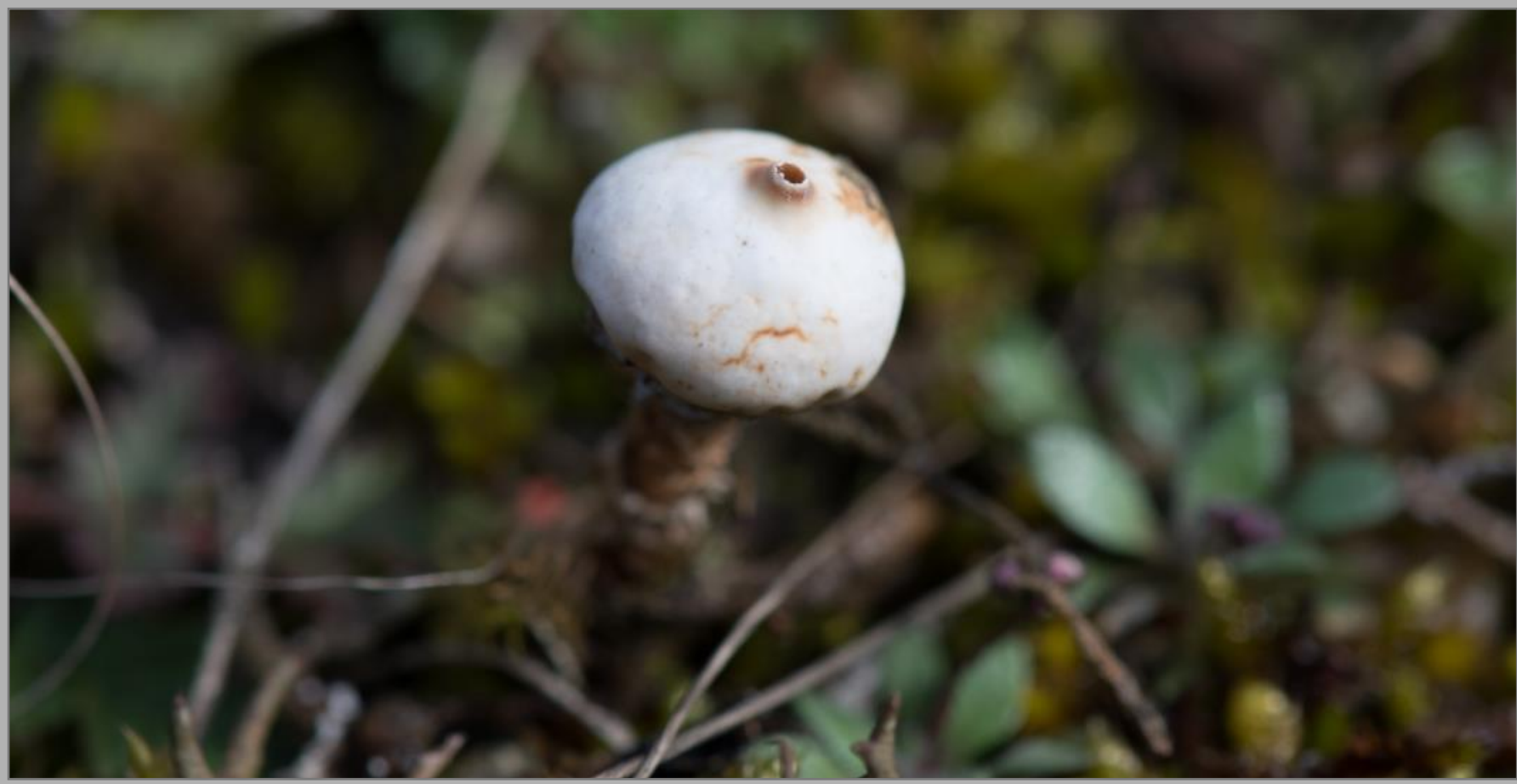

Tulostoma sp. Photo: J. Dengler. 